\title{
Technological Diffusion and Its Effects on Social Inequalities
}

\author{
Manuela Magalhães*and Christian Hellström \\ University of Warwick and University of Aalto
}

9th April 2011

\begin{abstract}
In spite of the intensive debate about the effects of skill-biased technology change (SBTC), its general equilibrium effects on the accumulation of skills and labor supply have been neglected. To analyze the full effects of the skill-biased technology diffusion on income inequality, labor and skills supply, we build a dynamic general equilibrium model, where growth is driven by skill-biased technology diffusion. Households have forward-looking expectations, and demonstrate an innate and idiosyncratic acquisition of skills. Contrary to pure technology progress models, technology diffusion models provide an explanation for the slowdown of the skill premium in the 70s compatible with the slow productivity growth. We find that first, technology diffusion raises the demand for skills and, consequently, the supply of skills. Second, skill-biased technology diffusion explains both the slowdown and the sharp increase of the skill premium observed in the 70 s and 80 s, respectively. In spite of the slowdown of the skill premium in the $70 \mathrm{~s}$, households anticipate the speed up of the technology diffusion and raise their investment in education, even during the economic slowdown. Therefore, the skills supply has continually increased since the 70s. Through a calibration exercise, we replicate the US trends for the skill-premium, skills supply, unskilled wages, consumption inequality and labor supply.
\end{abstract}

JEL classification: E24,J22,J23,J24,J31.

Keywords: Skill-Biased Technical Change, heterogeneous agents, inequality.

\footnotetext{
*We gratefully acknowledge financial support from Portuguese Science and Technology Foundation (Magalhaes) and European Commission through the Astrodynamics Network (Hellström). We thank Herakles Polemarchakis, Michael McMahon, Peng Sui, and participants of the Symposium of the Society for Nonlinear Dynamics and Econometrics (2011), EEA-ESEM (2011) and the University of Warwick seminar for their valuable comments and suggestions. This is a work in progress and comments are welcome. Correspondence: Manuela Magalhães, Department of Economics, Room S1.99, University of Warwick, Coventry, CV4 7AL, U.K. E-mail address: r.m.f.magalhaes@warwick.ac.uk. Christian Hellström, Department of Mathematica and System Analysis, Aalto University, Espoo, Finland. E-mail address: christian.hellstrom@aalto.fi
} 


\section{Introduction}

Income inequality has drastically increased in the last 30 years, in particular between workers with different education levels. On average, income inequality has increased since the 1970s in a large number of OECD countries, such as the UK, the US, Australia, the Netherlands, Denmark, and Sweden. From 1979 to 1995, income inequality grew in 12 out of the 19 countries analyzed by Gottschalk and Smeeding (2000), although the trend was not constant. In most of these countries, the inequality receded throughout the seventies and became more pronounced between the mid-80s and mid-90s. As Figure 1 shows, in the US the skill premium (SP), which is the wage of skilled relative to unskilled labor, has increased in spite of the sharp increase in the supply of skilled individuals in the last thirty years.

Despite the popularity of the pure technology hypothesis $($ Acemoglu $(2002))$ for the income inequality evolution, its predictions are inconsistent with the empirical evidence. The counter-factual prediction for wages of low skilled workers and productivity growth open the door for alternative explanations. Therefore, the skill-biased technology diffusion hypothesis accounts for both the income inequality and low productivity along the first years of its diffusion. Beyond that, there are no attempts in the literature to quantify the effect of skill-biased technology into the skills supply evolution in a context of a general equilibrium model. People base their schooling choices on expected earnings of different skilled occupations. Hence, in a general equilibrium, a skill-biased technology diffusion raises the demand for skilled workers, which may lead to an increase of skilled wages. Thus, forward-looking individuals with elastic labor decisions might change their time allocation between production and schooling activities. Because of the links between technology diffusion and education, the general equilibrium framework provides a joint explanation for skill premium and skills supply evolution.

Pure technology models assume that skills supply evolution is a consequence of the baby boom. However, the income inequality measure is the ratio between wages of workers with and without a college degree. As no one is born with a college degree, at the beginning of the technology diffusion, individuals differ in their initial skill endowment and their utility of education. So, individuals rationally decide whether to get a college degree or not. Contrary to most of the theoretical skill-biased literature that treats either skills supply or technology or both as exogenous, we believe that the standard microeconomic foundations behind the human capital investment theory (Ben-Porath (1967)) cannot be neglected when addressing this puzzle.

In this paper, we analyze the general equilibrium impact that a skill-biased techno- 


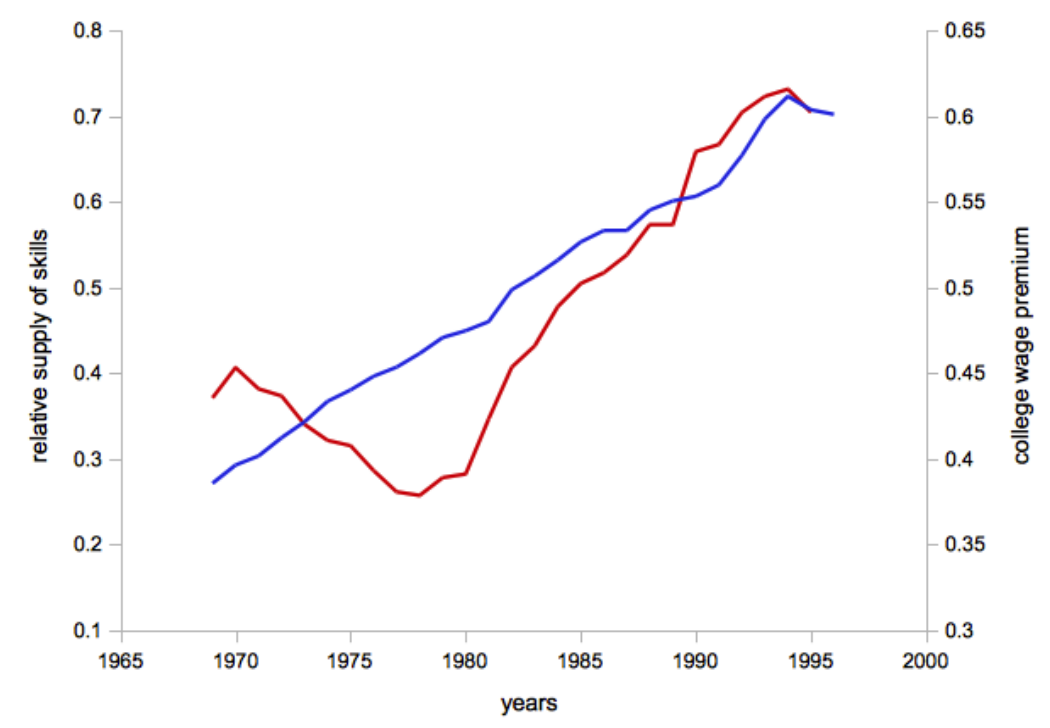

Figure 1: The behaviour of the logarithm of the college premium and relative skills supply.

Adapted from: Acemoglu (2002). College wage premium: solid line. Relative supply of skills: dashed line.

logy diffusion has on the skill premium and skills supply. Educational choices and elastic labor supply affect the skill premium via changes in the relative skilled labor, while skillbiased technology diffusion affects skill premium via changes in the labor demand. In addition, the expected rise in high-skill individuals also affects the current schooling choices. Our model includes three key characteristics. First, there is the appearance of a new technology, which is more productive and skill-biased. This technology requires skilled workers and diffuses throughout all sectors of the economy. This new technology requires a process of experimentation and adaptation, which initially delays its diffusion. Afterwards, due to social learning effects, we observe a speed-up of its diffusion. Second, when this technology starts its diffusion there is ex ante heterogeneity of individuals. A proportion of individuals already has the skills (college degree) required by this technology. The remaining individuals might acquire skills through investing in schooling activities, which has a disutility cost. Third, individuals have forward-looking expectations and allocate their time between production and school, based on their expected future wage differential. However, with the diminishing returns on education, the productivity of schooling activities is smaller than one. This productivity level ensures that individuals do not get a degree immediately, as this takes time. 
Under this theoretical framework, we are aiming for the transitional dynamic path between two steady states. The economy is in transition between two types of technologies. The skill-biased technology (new) and the existent technology (old). We calibrate the model to the US economy in 1969 in order to quantify the effects of skill-biased technology diffusion and human capital endogenous decisions on the skill premium and skills supply evolution in the last 30 years.

We find that the skill-biased technology diffusion jointly with the endogenous human capital accumulation hypothesis reproduces the trends observed for the skill premium, namely for the slowdown and the sharp increase, and the skills supply from 1969 to 1996. According to our model, and during the slowdown, there is a fall of 14 (real 12) and a rise of 11 (real 16) percentage points in the skill premium and relative skills supply, respectively. During the economic expansion, our model predicts a rise of 28 percentage points for both skill premium and skills supply. We overestimate skills supply, however, and our model still accounts for 90 percent of the real value of the skill premium and overestimates by 15 percent the real value of the relative skills supply in 1996 .

Since SBTC uses human capital as input and agents are forward-looking, we ask whether the technology diffusion is able to explain both the SP and skills supply evolution. We address these issues in model M. In M we consider a dynamic general equilibrium model with forward-looking heterogeneous agents, leisure-labor decisions, and human capital accumulation. We focus on the differences between workers before and after entering the labor market, accounting for pre-labor market investments (schooling) and job market investments (training). M replicates both the slowdown and the increase in the SP observed in the USA since 1969. In addition, we are concerned with the increase in the supply of skills, as observed in the USA: the skills supply has increased significantly between 1950 and 2000 (cf. Table 1), whereas the actual GPT has started its diffusion around the sixties. We also provide an explanation for the skills behavior. Apart from simulating the SP correctly, M replicates the evolution of skills supply, providing an explanation for the evolution of both the SP and the skills supply over the last thirty years.

The remainder of this paper is organized as follows. Section 2 discusses the historical background and the literature. Section 3 describes the optimization problem of companies in a monopolistic competition with two technologies, in which the new technology is more productive than the old one. Section 4 describes the consumer household problem and general-equilibrium model for the economy, labeled M. M defines a dynamic general equilibrium with leisure-labor decisions and endogenous evolution of skills through the accumulation of human capital. Section 5 presents the sensitivity analysis and section 
6 summarizes main results, and concludes our study. More details on some of the calculations are presented in appendix $\mathrm{A}$, and information on the algorithms used can be found in appendix B.

\section{Historical Background and Related Literature}

In the US the economic inequality has greatly expanded since 1970. The relative wage of college educated workers to high school educated has increased since 1970 despite the large increase of the relative supply of college educated workers. Between 1915 and 1950, the college wage premium fell, but afterwards increased, in particularly after 1980 (Table 1). However, the relative supply of skilled workers grew along all period, although we observe of slowdown of its growth rate after 90s.

\begin{tabular}{|c|c|c|}
\hline Period & $\begin{array}{l}\text { Change in the } \\
\text { relative wage }\end{array}$ & $\begin{array}{l}\text { Change in the } \\
\text { relative supply }\end{array}$ \\
\hline $1915-40$ & -0.56 & 2.82 \\
\hline $1940-50$ & -1.86 & 2.69 \\
\hline $1950-60$ & 0.83 & 3.23 \\
\hline 1960-70 & 0.69 & 2.86 \\
\hline $1970-80$ & -0.74 & 4.91 \\
\hline 1980-90 & 1.51 & 2.69 \\
\hline 1990-00 & 0.58 & 2.26 \\
\hline 2000-05 & 0.50 & 1.99 \\
\hline
\end{tabular}

Table 1: Changes in the college wage premium and supply of college-educated workers: 1915-2005. The shown figures are the annual log changes $\times 100$.

This puzzle has been studied by many economists, and several explanations have been put forward for the increase in inequality. However, there are some stylized facts such as the decrease of unskilled wages, the increase of college educated people, the elasticity of substitution between skilled and unskilled, the non substantial increase of productivity that are not compatible with the main explanation for the SP, namely the technology progress model.

Previous explanations for this puzzle go from trade theory until SBTC. A first explanation is based on Heckscher-Ohlin theory, in which globalization is deemed responsible for the rise in the demand for skilled labour in the developed countries, where skilled labour is cheaper than in developing countries. Unfortunately, the trade liberalization 
is not supported by evidence 1 ,

A second explanation is associated with institutional changes, such as de-unionization. As unionization is generally positively correlated to wage contraction, the de-unionization is perceived by Card (1996) and Machin (1997) as the driving force behind the increase in the wage inequality. However, their argument is seriously flawed, because de-unionization started in the USA during the 1950s, at which time the wage inequality was relatively stable 2

A third and final class of explanations pertains to a rapid skill-biased technology chang $\biguplus^{3}$ (SBTC), that is, a sudden shift in technology production that favours skilled labour. Krussel and Violante (2000), using a neoclassical framework argue that the complementary of skilled labour and physical equipment - contrary to unskilled labour - is the main reason for the increase in the SP. On the one hand, however, they remain unable to explain the acceleration of skill-biased technologies, while, on the other hand, they predict that a relative price decline of production equipment goods should be followed by an enhanced growth in the productivity, on the premise that capital and skills be complementary, which is not supported by empirical evidence Aghion and Howitt (2002)).

Additionally, all these solutions fail to explain the inequality slowdown observed in the seventies at a time of a steady increase in the skills supply.

Alternatively, two Schumpeterian growth mechanisms might also be used to address these issues. The first mechanism emphasizes the interplay between the supply of skilled labour and the endogenous rate of innovation. Basically, the increase in the labour supply is the engine of innovation, and consequently the skill premium. Acemoglu $(1998,2002)$ argues that the increase in the relative supply of college-educated workers in the 1970s directed the technology change, during which it became more skill-biased than before because of a 'market size' effect. In the short run, the increase in skilled college laborers reduces their relative wages (i.e. a slowdown in the SP), which leads to two opposing

\footnotetext{
${ }^{1}$ Krugman and others argue that it is difficult to imagine that trade could have had such an impact on the wage inequality in the USA, especially since trade with non-OECD countries is less than $2 \%$ of the GDP. Moreover, a fall in the prices of less skill-intensive goods in comparison to more skill-intensive ones is not observed, as predicted by this theory.

${ }^{2}$ Although trade and institutional changes fail to explain the recent evolution of the wage inequality, they might be relevant to explain the technology change direction.

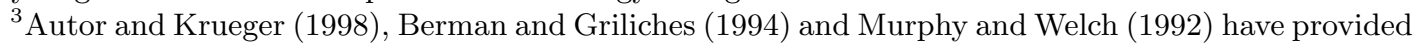
evidence in favour of the SBTC.

${ }^{4}$ In Krussel and Violante (2000), the SBTC reflects the growth of the equipment stock and, on the assumption that capital and skills be complementary, this may be important in explaining the wage inequality, because the equipment stock has been growing. Krussel and Violante (2000) consider a three factor production function as Stokey and Lucas (1996), in which the elasticity of substitution of capital equipment and unskilled labour is higher than that between capital equipment and skilled labour.
} 
effects on the relative profitability of skill-biased products. First, the decrease of the SP reduces the relative price of skill-biased products, and consequently the relative cost per unit that can be saved by quality improvements. This is the substitution effect, which causes the economy to follow a downwards-sloping relative demand curve. Second, the increase in the skills supply implies that in equilibrium there is a relative increase in the quantity of skill-intensive products, so the per-unit gain of a quality improvement increases. This is the 'market size' effect, also known as the directed technology effect, which dominates when the elasticity of substitution is large.

Yet Acemoglu falls short of a satisfactory explanation of all issues involved, too. Firstly, he does not offer an explanation as to why the wage inequality decreased during other historical episodes of sustained increases in the supply of educated laborers. Indeed, Goldin and Katz (1999) and Katz and Autor (1999) show that despite a pronounced increase in the skilled-labour supply between 1915 and 1950, following the high-school movement, the relative wage of college-educated workers fell continuously during the first half of the century (see Table 1). Secondly, Acemoglu presupposes the overall level of innovation and the increase in the relative supply of skills necessary to speed up the SBTC, attributing the increase in the relative supply of skills to the post-war baby boom. Still, one can only but wonder why the individuals choose to invest specifically in a college education. Third, empirical evidence contradicts the R\&D-based models of growth, which predict that the innovation rate increases with the supply of skills, as considered by Acemoglu. Jones (1995) points out that the productivity growth has been slow, especially from the mid-1970s through to the early 1980s, although there has been a substantial increase in education and R\&D in the OECD countries over the past fifty years. Fourth, Acemoglu (2002) only generates an increasing SP if the substitutability between skilled and unskilled workers is greater than 2, which some empirical studies have shown to be around 1.67 (Krussel and Violante (2000)). Finally, pure technology progress models are unable to replicate the reduction of unskilled wages over time.

Another way to reconcile market size theory with the evidence regarding the productivity is to assume that there is a long learning period before technology becomes effective. Thus, the aggregate productivity slowdown is due to the time necessary to produce and develop the new technological paradigm, generally called the General Purpose Technology (GPT). This explanation leads us to the second Schumpeterian growth mechanism, which is based on the idea that the GPT diffuses through the industrialized economies. Greenwood and Yorukoglu (1997) point out that the diffusion of a new GPT in the field of information and communication technology (ICT) increases the demand for skills when the new GPT diffuses throughout the economy, because experimentation 
and adoption require more skilled labour, which accounts for the slowdown and increas 5 in the SP. At same time, the adoption, diffusion, learning and improvement costs justify the slow productivity growth. Howitt (1998) argues that induced obsolescence is another channel through which the introduction of a new GPT can cause a long-lasting slowdown in the observed growth rate. Aghion (2002) shows, in a partial-equilibrium framework, that the technology diffusion model, in which economic growth is based on a sequence of quality-improving innovations that destroy the profits of previous ones, provides an important explanation for the connection between the slowdown of the increase in the $\mathrm{SP}$ and the continued increase in the relative supply of skills. Nevertheless, Aghion does not consider a general-equilibrium model, so that it remains unverified whether the SBTC diffusion is able to replicate the SP slowdown as well as the increase in the relative supply of skills, in the case of elastic labour decisions. Besides the general equilibrium effects, also discrete schooling choices haven't been considered into this context of skilled biased technology to analyze the dynamic evolution of skills supply and premium.

\section{Model}

We present the our idea behind the dynamic model M. The impact of the SBTC diffusion is examined on the households' labour supply decisions and investments on education. The labour supply decisions due to population changes are shown to have dramatic effects on the growth and business cycles. Therefore, the effect of labour supply decisions on the SP cannot be swept under the carpet in a diffusion model, as previously done.

Here, we develop a cyclical growth model based on the work of Helpman and Trajtenberg (1994). We add heterogeneous ${ }^{6}$ agents, similar to Aghion (2002). Our contribution consists of exploring, besides consumption, the effects of leisure-labour decisions. We introduce human capital accumulation, a feature previously not incorporated in similar models. Furthermore, we attempt to find the dynamic transition path for a neoSchumpeterian dynamic general-equilibrium model without limiting ourselves to steady-

\footnotetext{
${ }^{5}$ Technology diffusion might also explain the evolution in the first half of the twentieth century. We argue that is not an increase in the relative skills supply that directs the technology, as assumed by Acemoglu, but the overall level of skills in a economy. Although there can be an increase in the relative skills supply demanded by research activities, the economy's skill level is insufficient an incentive for an SBTC. Therefore, in the first half of twentieth century, the technology developed was unskilledbiased. However, this technology implementation required skilled laborers as well, so that initially the $\mathrm{SP}$ increased, though essentially its diffusion gained momentum due to the demand for unskilled workers, causing a decrease in the SP.

${ }^{6}$ The heterogeneity is restricted to two types, skilled and unskilled, making the model more tractable and compatible with the largest transition observed, which is high-school-educated and college-educated workers. In the USA, the largest transition in the tax brackets also occur for these groups.
} 
state analyses.

The fundamental principle of technological diffusion models is that a new GPT does not come ready to use; it requires a new set of intermediate goods and the economy must wait until a critical mass of intermediate components has been reached. Once it is profitable to switch, firms move to the new GPT.

The analysis of the transitional dynamics between two steady states, as studied by Conesa and Krueger (1999), Auerbach and Kotlikoff (1987), and Huang et al. (1997), forms the basis of the research we present here. It is important to note that in the dynamic model $\mathrm{M}$, we cannot apply the logic of the aforementioned people, because initially our endogenous state variable is unknown, and because we do not necessarily have a steady state to begin with. To alleviate these issues, we have developed our own algorithm to compute the solution numerically.

\subsection{Population}

The uniformly distributed heterogeneous population of size $L_{t}$ at (discrete) times $t=$ $0, \ldots, T$ consists of two subpopulations $i=i^{\mathrm{u}} \cup i^{\mathrm{s}}$. The labels 's' and ' $\mathrm{u}$ ' designate the skilled and unskilled subpopulations, respectively. Let $L_{t}^{\mathrm{s}}$ and $L_{t}^{\mathrm{u}}$ denote skilled and unskilled workers at time $t$, respectively. Each individual is finitely lived, and endowed with one unit of flow labour, and $L_{t}(i)$ denotes the flow of the labour supply. The subpopulations of either type are endogenously determined as a result of schooling and/or training investment in M.

The population of skilled and unskilled individuals are fractions $m_{t}$ and $\left(1-m_{t}\right)$ of the total population, respectively:

$$
\begin{aligned}
L_{t}^{\mathrm{s}} & =m_{t} L_{t}, \\
L_{t}^{\mathrm{u}} & =\left(1-m_{t}\right) L_{t} .
\end{aligned}
$$

Assumption 1. The number of skilled workers increases, and the number of unskilled workers decreases over time; the population of skilled workers evolves according to a geometric distribution, that is

$$
m_{t}=1-\left(1-m_{0}\right)(1-p)^{t}
$$

where $0<m_{t}<1, m_{0}$ is the initial proportion of skilled workers, and $p$ is the probability of becoming skilled in the next period, which is given by the education production function. 


\section{$3.2 \quad$ Firms}

The diffusion of a new GPT consists of a wave of secondary innovations creating new and improved products or processes in a specific sector, which are adaptations of the same GPT from other sectors. At period $t$ there is a continuum of firms $j$, distributed uniformly on the interval $[0,1]$. Of these firms, there are the ones labelled 'new' and the the ones labelled 'old' firms, these are the firms using the new and old GPTs, respectively. Let $n_{t}$ denote the proportion of firms that are already applying the new GPT, and hence $\left(1-n_{t}\right)$ is the proportion of firms that are still using the old GPT. The firms applying the new GPT employ skilled workers, and the firms applying the old GPT employ both skilled and unskilled workers; the new GPT requires skilled labour. So, as the GPT permeates the economy, the demand for skilled labour increases. The diffusion may take some time to set in, but once it starts, it tends to pervade over a relatively short time. Afterwards there is an acceleration of the diffusion, and consequently the demand for skilled labour.

A firm to move from the old to the new GPT must acquire a 'template', experiment, and succeed on its experimentation. The firms' transition from the old to the new GPT is given by an exogenous Poisson distribution. The reason that the diffusion of a new technology follows a nonlinear and logistic path has to do with the complementarity, or network externalities between sectors, and social learning effects. Complementarity, or network externalities between sectors, are due to some exogenous factors that may delay the transition to the new GPT, such as the increase in real labour costs, trade liberalization, or the intensification of the product market competition. Social learning effects are related to learning processes; firms learn to use the new technology not only because they are using it, but also from the experience gathered in other sectors where the technology has already been applied. This so-called threshold effect in cross-sector imitation (Aghion, 2002) implies that the larger the proportion of firms that have already implemented the new GPT, the more the knowledge and experience there is available, and therefore, the greater the benefits to firms that intend to use the new technology. This snowball effect accelerates the diffusion, and thus the demand for skilled labour, which in turn increases the skill premium.

Assumption 2. The evolution of $n_{t}$ is given by the difference equation

$$
n_{t+1}=n_{t}+\left(1-n_{t}\right) \lambda
$$

which follows a (cumulative) Poisson distribution, where $\lambda$ is the arrival rate of the 
template for the new GPT.

Equation (3) simply states that the current proportion of firms applying the new GPT equals the proportion of firms that have applied the GPT previously, plus the firms that have recently moved from the old technology to the new one. Here, $n_{0}>0$.

\subsection{Market Clearing Conditions}

Whenever a new technology is adopted, there are initially too few firms using it to absorb the entire skilled labour force, which means that some skilled workers are to be employed by the old firms at the same wages as their unskilled colleagues. After the initial phase, the number of sectors using the new technology is already large enough to take up all the skilled workers, and thus the labour market becomes segmented; unskilled workers can only work in the sectors using the old technology.

Assumption 3. Markets are not segmented at the beginning of the implementation of the new technology, but they are segmented after some time.

When the labour market is unsegmented, there is only one labour market clearing condition. We can then write the labour market condition as

$$
L_{t}^{h}=\int l_{t}(i) L_{t}(i) \mathrm{d} i=\int x_{t}(j) \mathrm{d} j=\left(1-n_{t}\right) x_{t}^{\text {old }}+n_{t} x_{t}^{\text {new }},
$$

where $l_{t}(i)$ is the number of hours of work supplied by either class of workers, and $x_{t}^{\text {new }}(j)$ and $x_{t}^{\text {old }}(j)$ denote the labour demands by firms using the new technology and old one, respectively.

As firms using the new GPT are more productive than the ones using the old GPT, the skilled workers are employed at higher wages, that is $w^{\mathrm{s}}>w^{\mathrm{u}}$, where $w^{\mathrm{s}}$ denotes the real wage of skilled workers, and $w^{\mathrm{u}}$ the real wage of unskilled workers. Therefore, once the labour market is segmented, there are two labour market clearing conditions, one for the skilled workers, and other one for the unskilled workers:

$$
\begin{aligned}
& L_{t}=L_{t}^{\mathrm{s}} l_{t}^{\mathrm{s}}=n_{t} x_{t}^{\text {new }}, \\
& L_{t}=L_{t}^{\mathrm{u}} l_{t}^{\mathrm{u}}=\left(1-n_{t}\right) x_{t}^{\text {new }},
\end{aligned}
$$

where the superscript $\mathrm{h}$ indicates the total amount of hours of labour, and obviously $L_{t}=L_{t}^{\mathrm{s}}+L_{t}^{\mathrm{u}}$. Here, and henceforth we shall suppress the arguments $i$ and $j$ of these and related functions whenever mathematically unambiguous. 


\subsection{Final Sector}

There is a unique final good produced with the aid of the GPT, and a continuum of intermediate goods $x_{t}(j)$ compatible with the GPT in use. The final product is made by 'labour' according to the constant-returns technology and a constant elasticity of substitution 7 (CES):

$$
Y_{t}=\left[\int_{0}^{1}\left[A(j) x_{t}(j)\right]^{\alpha} \mathrm{d} j\right]^{\frac{1}{\alpha}},
$$

with $\alpha>0$. Here, $A(j)$ is the productivity level of the firms, where $A(j)=1$ if the firms are applying the old GPT and $A(j)=\gamma>1$ if the firms have successfully innovated, and they are applying the new GPT. Consequently, $A(j)$ denotes the skill bias of the technology, and we assume that $A(j)$ is exogenously given. In addition, $x_{t}(j)$ is the flow of intermediate goods currently used in the production of the final good, using a one-for-one technology. Hence, $x_{t}(j)$ also denotes the labour demand flow.

Let $P_{t}$ and $P_{t}(j)$ denote the price of the final good and the prices of intermediate goods, respectively. The final-goods market is perfectly competitive, and the final producers take prices as given choosing $x_{t}(j)$ from the maximization of their profits $\Pi_{t}$ at time $t$ :

$$
\max _{x_{t}(j)} \Pi_{t}=\max _{x_{t}(j)}\left\{P_{t} Y_{t}-\int_{0}^{1} P_{t}(j) x_{t}(j) \mathrm{d} j\right\} .
$$

The final good is produced with either the old GPT $\left(x_{t}^{\text {old }}(j)\right)$ or the new GPT $\left(x_{t}^{\text {new }}(j)\right)$. The higher quality of these different products is reflected in productivity improvements of the final good. Since the production of the final good requires intermediate goods, the total cost is simply the quantity of intermediate goods used multiplied by their respective prices. From equation (6) it follows that all firms using the same GPT demand the same amount of labour, which enables us to rewrite the producers'

\footnotetext{
${ }^{7}$ The CES production function was introduced by Arrow et al. (1961), and the elasticity of substitution is defined as $1 /(1-\alpha)$. If $\alpha \rightarrow 0$, one obtains the the Cobb-Douglas production function; if $\alpha \rightarrow 1$, the production function becomes linear, so that intermediate goods are perfect substitutes. Finally, for $\alpha \rightarrow \infty$, the production function converges to the Leontief production function, and there is no substitution between intermediate goods.
} 
optimization problem as

$$
\begin{aligned}
\underset{x_{t}^{\text {old }}(j), x_{t}^{\text {new }}(j)}{\max } \Pi_{t}= & \\
\max _{x_{t}^{\text {old }}(j), x_{t}^{\text {new }}(j)}\left\{P_{t}\right. & {\left[\int_{0}^{1-n}\left(x_{t}^{\text {old }}(j)\right)^{\alpha} \mathrm{d} j+\gamma^{\alpha} \int_{1-n}^{1}\left(x_{t}^{\text {new }}(j)\right)^{\alpha} \mathrm{d} j\right]^{\frac{1}{\alpha}} } \\
& \left.-\left[\int_{0}^{1-n} P_{t}^{\text {old }}(j) x_{t}^{\text {old }}(j) \mathrm{d} j+\int_{1-n}^{1} P_{t}^{\text {new }}(j) x_{t}^{\text {new }}(j) \mathrm{d} j\right]\right\} .
\end{aligned}
$$

From the (necessary) first-order conditions (FOCs), also known as the Karush-KuhnTucker optimality conditions, of this unconstrained optimization problem 8 , we obtain the demands for the intermediate goods using either the new or old GPT. The demand by the final producers of intermediate goods created with the new technology is

$$
x_{t}^{\text {new }}(j)=\gamma^{\frac{\alpha}{1-\alpha}}\left(\frac{P_{t}^{\text {new }}(j)}{P_{t}}\right)^{\frac{1}{\alpha-1}} Y_{t} .
$$

The demand for intermediate goods by final producer produced using the old technology is given by

$$
x_{t}^{\text {old }}(j)=\left(\frac{P_{t}^{\text {old }}(j)}{P_{t}}\right)^{\frac{1}{\alpha-1}} Y_{t} .
$$

Intermediate goods produced by using the new technology increase the efficiency of the manufacture of the end product. Similarly, the demand for $x_{t}^{\text {new }}(j)$ is a positive function of the technological productivity level. The increase in the demand for intermediate goods produced by using the new GPT is greater than the increase in the productivity level; the higher the substitutability between intermediate goods $(0<\alpha<1)$, the higher the demand for goods produced with the new technology.

\subsection{Intermediate Sector}

The intermediate sector only uses labour in its production. The intermediate products can be manufactured using either the new or the old technology. The production function of the intermediate sector is linear in the labour for one-for-one technology. Firms using the new GPT have skilled workers to produce $x_{t}^{\text {new }}(j)$, whereas firms producing $x_{t}^{\text {old }}(j)$ can employ both types of workers. In the case that the market is not segmented (yet),

\footnotetext{
${ }^{8}$ See appendix $\mathrm{A}$ for details.
} 
the skilled workers also offer labour to firms creating $x_{t}^{\text {old }}(j)$, so that production function retains linearity and the one-for-one technology property. Hence, the demands $x_{t}^{\text {new }}(j)$ plus $x_{t}^{\text {old }}(j)$ equal the demands for $L_{t}$ plus $L_{t}$. Once the labour market is segmented, the skilled work force is completely hired by firms using the new GPT. In that case, production function is given by

$$
x_{t}^{\text {new }}=L_{t} .
$$

Analogously, the unskilled workers can only work for firms applying the old GPT. Therefore, the corresponding production function reads

$$
x_{t}^{\text {old }}=L_{t} \text {. }
$$

These intermediate producers are monopolist:9? which means that they dictate the price levels. Because capital accumulation is absent from the model, there are no fixed costs; the only cost available is the labour. The optimization problem for these producers is

$$
\max _{P_{t}(j)}\left\{P_{t}(j) x_{t}(j)-w_{t}(i) L_{t}^{\mathrm{h}}(i)\right\} .
$$

With equations (8) we can modify the above maximization for firms using the new GPT

$$
\max _{P_{t}^{\text {naw }}(j)}\left\{\left(P_{t}^{\text {new }}(j)-w_{t}^{\mathrm{s}}(i)\right) \gamma^{\frac{\alpha}{1-\alpha}}\left(\frac{P_{t}^{\text {new }}(j)}{P_{t}}\right)^{\frac{1}{\alpha-1}} Y_{t}\right\},
$$

and for firms using the old GPT

$$
\max _{P_{t}^{\text {old }}(j)}\left\{\left(P_{t}^{\text {old }}(j)-w_{t}^{\mathrm{u}}(i)\right) \gamma^{\frac{\alpha}{1-\alpha}}\left(\frac{P_{t}^{\text {old }}(j)}{P_{t}}\right)^{\frac{1}{\alpha-1}} Y_{t}\right\},
$$

From the related FOCs (see Appendix A), we obtain the relative prices for the firms using the new $\operatorname{GPT}\left(p_{t}^{\text {new }}(j) \equiv P_{t}^{\text {new }}(j) / P_{t}\right)$,

$$
p_{t}^{\text {new }}=\frac{w_{t}^{\mathrm{s}}}{\alpha},
$$

\footnotetext{
${ }^{9}$ Monopolistic power is introduced because it takes time to implement the new technology. Hence, the differentiated intermediate goods explain this monopolistic power and entrepreneurs have incentives to invest in this new technology.
} 
and likewise for the firms using the old GPT $\left(p_{t}^{\text {old }}(j)=P_{t}^{\text {old }}(j) / P_{t}\right)$,

$$
p_{t}^{\text {old }}=\frac{w_{t}^{\mathrm{u}}}{\alpha}
$$

It is worth noting that there is a mark-un ${ }^{10}$ over the marginal cost. The higher the elasticity of substitution between intermediate goods, the smaller the mark-up. If the labour market is segmented, that is if $w_{t}^{\mathrm{s}}>w_{t}^{\mathrm{u}}$, then $p_{t}^{\text {new }}>p_{t}^{\text {old }}$, otherwise $w_{t}^{\mathrm{s}}=w_{t}^{\mathrm{u}}$, so that $p_{t}^{\text {new }}=p_{t}^{\text {old }}$. Suppose, for instance, that skilled employees are unable to find a job in the sectors using the new GPT or that the wages paid by these sectors are still lower in comparison with the wages paid by sectors utilizing the old GPT. Rationally, these professionals shall offer their labour to firms in sectors using the old GPT. Therefore, at the outset of the technology diffusion, the labour market is not segmented, as assumed previously, so that $w_{t}^{\mathrm{s}}=w_{t}^{\mathrm{u}}$.

Substituting equations (9a) and $9 \mathrm{~b}$ ) into equations $7 \mathrm{a}$ and $7 \mathrm{~b}$, respectively, we obtain the demand for intermediate goods and labour as functions of the wages $w_{t}$ and the output $Y_{t}$,

$$
\begin{aligned}
x_{t}^{\text {new }} & =\left(\frac{w_{t}^{\mathrm{s}}}{\alpha \gamma^{\alpha}}\right)^{\frac{1}{\alpha-1}} Y_{t}, \\
x_{t}^{\text {old }} & =\left(\frac{w_{t}^{\mathrm{u}}}{\alpha}\right)^{\frac{1}{\alpha-1}} Y_{t},
\end{aligned}
$$

for firms using the new and old GPT, respectively. Equations 10 state that the higher the economy output, the technology productivity $\gamma$, and the substitutability between intermediate goods, the higher the demand; the higher the labour cost, the smaller the demand for intermediate goods.

Substituting the relative prices into the profit function, we find the profits for both types of firms:

$$
\begin{aligned}
\Pi_{t}^{\text {new }} & =\frac{1-\alpha}{\alpha} w_{t}^{\mathrm{s}} x_{t}^{\text {new }}, \\
\Pi_{t}^{\text {old }} & =\frac{1-\alpha}{\alpha} w_{t}^{\mathrm{u}} x_{t}^{\text {old }}
\end{aligned}
$$

${ }^{10}$ Gali (1995) and Seegmuller (2007) have analyzed a monopolistic competition model in a dynamic setting, in which the mark-up factor depends on the number of firms, more specifically on the number of varieties of firms. Since our model is a quality-improving growth model with a constant number of varieties, our mark-up does not depend on the number of varieties. Nevertheless, it would be interesting to explore exactly how mark-ups might diverge between the different sectors of the economy. 
The total amount of profits, is the sum of profits for both sectors, that is

$$
\Pi_{t}^{\text {total }}=\left(1-n_{t}\right) \Pi_{t}^{\text {old }}+n_{t} \Pi_{t}^{\text {new }}
$$

From equations 10 we find the skill premium

$$
\frac{w_{t}^{\mathrm{s}}}{w_{t}^{\mathrm{u}}}=\gamma^{\alpha}\left(\frac{x_{t}^{\text {new }}}{x_{t}^{\text {old }}}\right)^{\alpha-1}
$$

In the case of perfect substitutability among intermediate goods $(\alpha=1)$, the production function is linear and the skill premium 11 translates to an increase in the productivity of the new GPT. In the case of $(\alpha=0)$ the production function is the well-known CobbDouglas one, and the technology is not biased towards either labour factor; the SP is linear in the relative demand $x_{t}^{\text {new }} / x_{t}^{\text {old }}$. As noted before, if $\alpha \rightarrow \infty$, then the production function reduces to the Leontief production function, and there is no substitutability between intermediate goods, so that the SP tends to infinity. In instances of imperfect substitutability, we observe two special cases. If $\alpha>1$, the intermediate goods are gross complements, so that both the skill premium and the relative demand increase with the degree of substitutability. If $\alpha<1$, the intermediate goods are gross substitutes, for which the skill premium decreases.

Substituting the labour demand 10 into the respective labour market clearing conditions (5), we find

$$
\begin{aligned}
& w_{t}^{\mathrm{s}}=\alpha \gamma^{\alpha}\left(\frac{n_{t} Y_{t}}{m_{t} l_{t}^{\mathrm{s}}}\right)^{1-\alpha}, \\
& w_{t}^{\mathrm{u}}=\alpha\left(\frac{\left(1-n_{t}\right) Y_{t}}{\left(1-m_{t}\right) l_{t}^{\mathrm{u}}}\right)^{1-\alpha}
\end{aligned}
$$

in the case of segmented markets, and

$$
w_{t}=\alpha\left[\left(1+n_{t}\left(\gamma^{\frac{1}{1-\alpha}}-1\right)\right) \frac{Y_{t}}{l_{t}}\right]^{1-\alpha},
$$

in the case of unsegmented markets. We thus see that the wages of skilled and unskilled workers are determined by the productivity of the respective technologies, the degree of substitutability between the goods produced, the technology diffusion, the economic output, the education level of the society, and individual labour decisions.

\footnotetext{
${ }^{11}$ Please note that the skill premium $w_{t}^{\mathrm{s}}(i) / w_{t}^{\mathrm{u}}(i)=P_{t}^{\text {new }}(j) / P_{t}^{\mathrm{old}}(j)$ indicates the relative price of intermediate goods produced by the new and old technologies.
} 
Dividing equation (14a by $14 \mathrm{~b}$, we can rewrite the SP in terms of the labour supply:

$$
\frac{w_{t}^{\mathrm{s}}}{w_{t}^{\mathrm{u}}}=\gamma^{\alpha}\left(\frac{n_{t}}{1-n_{t}} \frac{1-m_{t}}{m_{t}} \frac{l_{t}^{\mathrm{u}}}{l_{t}^{\mathrm{s}}}\right)^{1-\alpha} .
$$

One easily verifies that for $\alpha=1$ the technology is not biased, and the skill premium is simply a constant, which reflects the additional efficiency of the new technology. For $\alpha>1$ (gross complements), the new technology is biased towards being unskilled 12 , Similarly, the SP increases with the relative weight of firms using the new technology, that is, the SP rises with the diffusion of the new GPT. Finally, for $\alpha<1$ (gross substitutes), the SP decreases as a function of the relative supply, or as a function of the relative weight of firms using the new technology. In addition, we have

Proposition 1. The SP rises with [(i)]

the scarceness of skilled workers, $\frac{\partial \ln w_{t}^{s} / w_{t}^{u}}{\partial \ln m_{t} /\left(1-m_{t}\right)}=\alpha-1$, which is the substitution effect; improvements in the technology, $\frac{\partial \ln w_{t}^{s} / w_{t}^{u}}{\partial \ln A^{\text {new }} / A^{\text {old }}}=\alpha$;

the diffusion of the new technology, $\frac{\partial \ln w_{t}^{s} / w_{t}^{u}}{\partial \ln n_{t} /\left(1-n_{t}\right)}=1-\alpha$; and the intensity of hours worked ${ }^{13}$ by skilled laborers relative to unskilled laborers: $\frac{\partial \ln w_{t}^{s} / w_{t}^{u}}{\partial \ln l_{t}^{s} / l_{t}^{u}}=$ $\alpha-1$.

Proof. The proof is straightforward from the SP equation (16).

The diffusion and hours effects, which is due to the elasticity of the labour supply, are considered by neither Acemoglu (2002) nor Krussel and Violante (2000).

Let $\hat{x}$ denote the growth rate of a variable $x$, and $y$ and $y$ be the output per hour worked by the skilled and unskilled labour forces, respectively. We then have the following

Proposition 2. The growth rates of the wages of the skilled and unskilled subpopulations

\footnotetext{
${ }^{12}$ This might be the type of technology diffusion associated with industrial revolution, which characterized the economic growth from the 19th century onwards to the 1960 s.

${ }^{13}$ One could introduce an efficiency index in the CES production function (equation (6)), which would catch the quality of the hours worked, and could be able distinguish the effect of working hours from the effect workers employed.
} 
are

$$
\begin{aligned}
& \widehat{w^{s}}=(1+\widehat{n}+\widehat{y}+\widehat{n} \widehat{y})^{(1-\alpha)}-1 \\
& \widehat{w^{u}}=(1+\widehat{1-n}+\widehat{y}+(\widehat{1-n}) \widehat{y})^{(1-\alpha)}-1,
\end{aligned}
$$

respectively.

Proof. See Appendix C.

The growth rate of the wages of the skilled individuals depends not only on the diffusion of the new technology throughout whole sectors of the economy, but also on the growth rate of the economic output per hour of work by the skilled workers. On the one hand, the growths of the skilled subpopulation and skilled labour supply reduces the skilled people's wages because of the law of demand and supply, whereas on the other, there is an indirect positive effect on the wages of the skilled, because it increase the output. Hence, the net effect of an increase in $m_{t}$ and $l_{t}^{\mathrm{s}}$ on $w^{\mathrm{s}}$ can be analyzed by their impact on $\hat{y}$.

Proposition 3. In an economy with a constant size of population and firms, the growth rate of the $S P$ is:

$$
\widehat{S P}=\left(\frac{1+\widehat{l^{u}}}{1+\widehat{l^{s}}} \frac{(1+\widehat{n})(1-n)}{1-n(1+\widehat{n})} \frac{1-m(1+\widehat{m})}{(1+\widehat{m})(1-m)}\right)^{1-\alpha}-1
$$

Proof. See appendix C

A growth of the technology diffusion as well as the the relative amount of work supplied by the skilled workers as compared to the unskilled ones 14 increases the growth rate of the SP (compare (32)), whereas a positive growth rate of skills diminishes the growth rate of the SP.

As one last step in the basic exposé of our model, we substitute the labour demand and wages (equations (14) or (15)) into the production function (6) to obtain for segmented markets

$$
Y_{t}=\left[\left(1-n_{t}\right)^{(1-\alpha)}\left(\left(1-m_{t}\right) l_{t}^{\mathrm{u}}\right)^{\alpha}+\gamma^{\alpha} n_{t}^{(1-\alpha)}\left(m_{t} l_{t}^{\mathrm{s}}\right)^{\alpha}\right]^{\frac{1}{\alpha}}
$$

\footnotetext{
${ }^{14}$ This effect has, to the best of our knowledge, not been studied by many researchers. Nevertheless, the empirical evidence shows that the number of hours supplied by individuals has changed over time and the individuals' lifetimes Erosa et al. (2009).
} 
and for unsegmented markets

$$
Y_{t}=\left[\left(1-n_{t}\left(1-\gamma^{\frac{\alpha^{2}}{\alpha-1}}\right)\right)\left(\frac{1+n_{t}\left(\gamma^{\frac{1}{1-\alpha}}-1\right)}{l_{t}}\right)^{-\alpha}\right]^{\frac{1}{\alpha}} .
$$

These equations give the output of the economy as functions of the labour rather than the intermediate goods.

\section{Households Optimization (M)}

Now we present the details of the dynamic model M. In M, the economy is populated by two different households, or agents: skilled and unskilled ones, both with lifetimes of $T$ periods. The individuals of the skilled agents are already skilled at the beginning $(t=0)$, and they remain so until the end $(t=T)$. Individuals from unskilled households start out being unskilled, and they may become skilled afterwards. The unskilled individuals are allowed to invest in education in order to climb up the skills ladder and become part of the skilled subpopulation. Households have preferences over their own consumption $c_{t}$ and leisure; the maximum number of working hours, that is the length of one day, is normalized to unity. Since all households maximize their expected lifetime utility rather than their instantaneous utility, they do not send all their members to school at the same time. These households have a probability 15

$$
p_{t+1}=a l_{t}^{\mathrm{e}},
$$

with $0<a<1$, of advancing at the next period, which is related to the number of members who acquire the attribute 'skilled' in their lives; these households obviously receive income from both types of work. This probability is directly related to the education production function, which is linear in hours invested on education. So, skilled agents allocate their time between leisure $\left(1-l_{t}^{\mathrm{S}}\right)$ and labour $\left(l_{t}^{\mathrm{S}}\right)$, whereas unskilled agents can now allocate their time between labour $\left(l_{t}^{\mathrm{u}}\right)$, education $\left(l_{t}^{\mathrm{e}}\right)$, and leisure $(1-$ $\left.l_{t}^{\mathrm{u}}-l_{t}^{\mathrm{e}}\right)$. Skilled workers can be employed by firms using either the new or the old technology, whereas their unskilled colleagues can only work for firms using the old technology. Identical economic agents maximize their utility function $u_{t}\left(c_{t}, l_{t}\right)$ in each period $t$, subject to their budget constraint. The utility function is strictly concave,

\footnotetext{
${ }^{15}$ Households might raise their human capital stock, that is, increase the proportion of skilled members tomorrow, by allocating a fraction of their time today to education or schooling.
} 
and increases with consumption and decreases with labour, and it satisfies the Inada conditions.

In addition, we require the following:

Assumption 4. Profits from intermediate sectors are distributed equally between the skilled and unskilled agents.

The households are assumed to be forward-looking, which means that they maximize their total expected (current and future) utility, taking into account an appropriate discount factor $0<\beta<1$ for future values. For the skilled households, the optimization problem reads

$$
\begin{gathered}
\max _{X^{\mathrm{s}}} \sum_{t=0}^{T} \beta^{t} u\left(c_{t}^{\mathrm{s}}, 1-l_{t}^{\mathrm{s}}\right), \\
\text { s.t. } c_{t}^{\mathrm{s}} \leq w_{t}^{\mathrm{s}} l_{t}^{\mathrm{s}}+\Pi_{t}^{\text {total }},
\end{gathered}
$$

where we have introduced the (feasible) set $X^{\mathrm{s}}=\left\{c_{t}^{\mathrm{s}}, l_{t}^{\mathrm{s}}\right\}_{t=0}^{T}$. Similarly, we have for the unskilled households,

$$
\begin{aligned}
& \quad \max _{X^{\mathrm{u}}}\left\{\sum_{t=0}^{T} \beta^{t}\left[\pi_{t}^{\mathrm{u}} u\left(c_{t}^{\mathrm{u}}, 1-l_{t}^{\mathrm{u}}-l_{t}^{\mathrm{e}}\right)+\pi_{t}^{\mathrm{s}} u\left(c_{t}^{\mathrm{s}}, 1-l_{t}^{\mathrm{s}}\right)\right]\right\}, \\
& \text { s.t. } c_{t}^{\mathrm{u}} \leq w_{t}^{\mathrm{u}} l_{t}^{\mathrm{u}}+\Pi_{t}^{\mathrm{total}} \\
& \quad c_{t}^{\mathrm{s}} \leq w_{t}^{\mathrm{s}} l_{t}^{\mathrm{s}}+\Pi_{t}^{\mathrm{total}}
\end{aligned}
$$

with $X^{\mathrm{u}}=\left\{c_{t}^{\mathrm{u}}, l_{t}^{\mathrm{u}}, l_{t}^{\mathrm{e}}\right\}_{t=0}^{T}$. Here $\pi_{t}^{\mathrm{u}}=1-\pi_{t}^{\mathrm{s}}$ denotes the probability that an unskilled individual $\left(\pi_{0}^{\mathrm{u}}=1\right)$ remains unskilled at period $t$. Obviously,

$$
\pi_{t+1}^{\mathrm{u}}=\pi_{t}^{\mathrm{u}}\left(1-p_{t+1}\right)
$$

which is a first-order ordinary difference equation that is solved by

$$
\pi_{t}^{\mathrm{u}}=\prod_{k=0}^{t-1}\left(1-p_{k+1}\right) .
$$

The fraction of skilled individuals now equals the fraction of individuals that have been skilled already in addition to the fraction of individuals that have become skilled recently. Mathematically, we write this statement as

$$
m_{t+1}=m_{t}+\left(1-m_{t}\right) p_{t+1}
$$


It is obvious that the decisions made by unskilled households today depend on the (expected) values of the variables in the future. Please note that because $a<1$, there is the possibility of 'failure' built in the model: even if the unskilled households send all their members to school, not all of them become educated (skilled).

The optimization problems introduced in this section are all finite horizon discretetime optimal control problems, where the 'state variables' are the probabilities $m_{t}$ and $n_{t}$, and the 'controls' are the consumptions and labour of both the skilled and unskilled agents, and the education. We may therefore write these optimal control problems as dynamic programs by virtue of the Bellman equation, which can be solved by backward induction. The result is summarized below.

Problem $1(\mathrm{M})$. For the skilled agents, the dynamic program reads

$$
\begin{aligned}
& \quad V_{t}^{s}\left(m_{t}, n_{t}\right)=\max _{c_{t}^{s}, l_{t}^{s}}\left\{u\left(c_{t}^{s}, 1-l_{t}^{s}\right)+\beta V_{t+1}^{s}\left(\left(m_{t+1}, n_{t+1}\right)\right\},\right. \\
& \text { s.t. } c_{t}^{s} \leq w_{t}^{s} l_{s, t}+\Pi_{t}^{\text {total }},
\end{aligned}
$$

and for the unskilled agents

$$
\begin{aligned}
& V_{t}^{u}\left(m_{t}, n_{t}\right)=\max _{c_{t}^{u}, l_{t}^{u}, l_{t}^{e}}\left\{u\left(c_{t}^{u}, 1-l_{t}^{u}-l_{t}^{e}\right)\right) \\
& \left.\quad+\beta\left(\left(1-a l_{t}^{e}\right) V_{t+1}^{u}\left(m_{t+1}, n_{t+1}\right)+a l_{t}^{e} V_{t+1}^{s}\left(m_{t+1}, n_{t+1}\right)\right)\right\}, \\
& \text { s.t. } c_{t}^{u} \leq w_{t}^{u} l_{t}^{u}+\Pi_{t}^{\text {total }}, \\
& c_{t}^{s} \leq w_{t}^{s} l_{t}^{s}+\Pi_{t}^{\text {total }} .
\end{aligned}
$$

The functions $V_{t}^{I}=V_{t}^{I}\left(m_{t}, n_{t}\right)$ are called the value functions, and they represent the 'utility-to-expect' functions, hence the appearance of the probability of becoming $\left(p_{t+1}\right)$ rather than being $\left(\pi_{t}^{\mathrm{s}}\right)$ skilled.

In order to solve $\mathrm{M}$ with the algorithm described in appendix B we have to restate the multi-objective recursive optimization problem $\mathrm{M}$ as a nonlinear programming problem, which we achieve by combining the value functions (with equal weights) into one objective function. 
As one can derive easily, the FOCs for M are

$$
\begin{aligned}
\frac{\partial u}{\partial c_{t}^{I}}-\lambda_{t}^{I} & =0, \\
\frac{\partial u}{\partial l_{t}^{I}}+\lambda_{t}^{I} w_{t}^{I} & =0, \\
\frac{\partial u}{\partial l_{t}^{\mathrm{e}}}+a \beta\left(V^{\mathrm{s}}\left(m_{t+1}, n_{t+1}\right)-V^{\mathrm{u}}\left(m_{t+1}, n_{t+1}\right)\right) & =0 .
\end{aligned}
$$

So, the skill premium is equal to the ratio of MRS between skilled and unskilled households..

The equations for the firms (1a)- 19) remain valid here, except that in equation (2) the labour supply is now a function of the inter-temporal income increment.

\subsection{Recursive Equilibrium}

In the presence of an exogenous technological diffusion $n_{t}$ and endogenous human capital accumulation $m_{t}$, we can aggregate the households' human capital accumulation, for we assume that all individuals are identical. We have two combined state variables $\left(m_{t}, n_{t}\right)$ obeying their discrete (update) maps. The state variables have to be defined in aggregate terms, because the households' decisions depend not only on their past decisions but also on future decisions. Therefore, the households not only require knowledge of their own states, but of the economy as a whole as well.

Definition 1. The recursive equilibrium for the economy in $M$ is a set of values for the skilled households $\left\{\bar{V}_{t}^{s}, \bar{c}_{t}^{s}, \bar{l}_{t}^{s}\right\}_{t=0}^{T}$ and the unskilled households, $\left\{\bar{V}_{t}^{u}, \bar{V}_{t}^{s}, \bar{c}_{t}^{u}, \bar{c}_{t}^{s}, \bar{l}_{t}^{u}, \bar{l}_{t}^{s}, \bar{l}_{t}^{e}\right\}_{t=0}^{T}$, a set of production plans for the firms $\left\{\bar{x}_{t}^{\text {new }}, \bar{x}_{t}^{\text {old }}\right\}_{t=0}^{T}$, a set of prices $\left\{\bar{w}_{t}^{s}, \bar{w}_{t}^{u}\right\}_{t=0}^{T}$, such that these solve problem 1 under the aforementioned assumptions.

So far, we have not specified the utility function, that is the objective function in the optimization problem 1. We take a non-separable, non-isoelastic utility function with preferences according to the Cobb-Douglas form (see e.g. Chari and Christiano, 1994). For the skilled households the utility function is simply the familiar Cobb-Douglas utility function (24). For the unskilled households, however, we take $u\left(c_{t}^{\mathrm{u}}, 1-l_{t}^{\mathrm{u}}-l_{t}^{\mathrm{e}}\right)$, as their leisure has been reduced to $1-l_{t}^{\mathrm{u}}-l_{t}^{\mathrm{e}}$, because of the time spent on education:

$$
u\left(c_{t}^{I}, 1-l_{t}^{I}\right)= \begin{cases}\frac{1}{1-\sigma}\left(\left(c_{t}^{I}\right)^{\eta}\left(1-l_{t}^{I}\right)^{1-\eta}\right)^{1-\sigma}, & \text { for } \sigma \neq 1, \\ \eta \log c_{t}^{I}+(1-\eta) \log \left(1-l_{t}^{I}\right), & \text { for } \sigma=1 .\end{cases}
$$


Here, $\eta \in(0,1)$ determines the relative importance of consumption in comparison with leisure, and $\sigma$ is the risk aversion of consumers. Related to these parameters are the coefficient of relative risk aversion, abbreviated CRRA, $\sigma \eta+1-\eta$, and and inter-temporal elasticity of substitution in consumption, or IES for short, $1 /(1-(1-\sigma) \eta)$.

Therefore, from the FOCs 23 for the Cobb-Douglas utility function, we obtain that

$$
\begin{aligned}
c_{t}^{\mathrm{u}} & =\frac{\eta}{1-\eta} w_{t}^{\mathrm{u}}\left(1-l_{t}^{\mathrm{u}}-l_{t}^{\mathrm{e}}\right), \\
c_{t}^{\mathrm{s}} & =\frac{\eta}{1-\eta} w_{t}^{\mathrm{s}}\left(1-l_{t}^{\mathrm{s}}\right) .
\end{aligned}
$$

for all $\sigma$.

Similarly, from FOCs and budget constraints, we get the the supply of working hours and hours spent on schooling activities:

$$
\begin{aligned}
& l_{t}^{\mathrm{s}} \geq \eta-(1-\eta) \frac{\Pi_{t}^{\mathrm{total}}}{w_{t}^{\mathrm{s}}}, \\
& l_{t}^{\mathrm{u}} \geq \eta-(1-\eta) \frac{\Pi_{t}^{\mathrm{total}}}{w_{t}^{\mathrm{u}}}, \\
& l_{t}^{\mathrm{e}} \geq \begin{cases}1-l_{t}^{\mathrm{u}}-\frac{1-\eta}{\beta a\left(V_{t}^{\mathrm{s}}-V_{t}^{\mathrm{s}}\right)} & \sigma=1, \\
1-l_{t}^{\mathrm{u}}-\frac{1-\eta}{\beta a\left(V_{t}^{\mathrm{s}}-V_{t}^{\mathrm{u}}\right)} \frac{c_{t}^{\mathrm{u}}}{u_{t}^{\mathrm{u}}}, & \sigma \neq 1\end{cases}
\end{aligned}
$$

where we have suppressed the functional dependencies for brevity.

We close this section by stating

Proposition 4. If the growths of the income and hour labour decisions are positively (negatively) correlated and $\widehat{S P}>0$, then the growth of the consumption inequality is greater (smaller) than the growth of the income inequality.

Proof. The proof is identical to that of proposition 2, only here

$$
\frac{\widehat{c^{\mathrm{s}}}}{c^{\mathrm{u}}}=\widehat{S P}+\frac{\widehat{1-l^{\mathrm{s}}}}{1-l^{\mathrm{u}}-l^{\mathrm{e}}}+\widehat{S P} \frac{\widehat{1-l^{\mathrm{s}}}}{1-l^{\mathrm{u}}-l^{\mathrm{e}}} .
$$

\subsection{Numerical Results}

In our model M, we assume that the technology diffusion takes forty years, and that all individuals live $T$ periods (years). The two classes of workers are interpreted as high- 
school-educated (unskilled) and college-educated ${ }^{16}$ (skilled) labour 17 . The skill premium is identified as the college premium, where the skilled laborers are defined in a similar way as in the works of Acemoglu (2002) and Autor and Krueger (1998).

All parameters have been calibrated to replicate observations from the US economy in the period 1969-2009, in particular the fraction of the higher educated labour force $\left(m_{t}\right)$ and the skill premium $\left(w_{t}^{\mathrm{s}} / w_{t}^{\mathrm{u}}\right)$. Preference parameters are calibrated to standard values used by Chari and Christiano (1994), Werning (2007), and Conesa et al. (2009). For the logarithmic utility function, we set $\eta=0.393$, and the annual discount factor $\beta=0.95$. Alternatively, we take $\sigma=2$ with $\eta=0.42$, as a consistency check. For the values of the technology parameters, we follow Aghion (1998); the degree of substitutability across intermediate goods $\alpha=0.8$, and the productivity improvement of the new technology $\gamma=1.5$. Regarding to the productivity of the investment in education, we set $a=0.65$, which relates directly to the dynamical transition probability $p_{t}$, as given by equation (20). Furthermore, we set the year 1969 as the initial steady-state. Thereby, the value for our initial state variable are the ones observed in the real data. So, we take $m_{0}=0.27$ and we assume $n_{0}=0.30$. The latter value is chosen to match the empirical value of the proportion of skilled workers 1969. The parameters of our model are summarized in the Table 2. We stress that the model is highly stylized, and that we are mainly concerned with the overall trends, especially the slowdown in the SP. Moreover, the results discussed here are merely the means to understand the effects of technology diffusion in a general-equilibrium framework that includes leisure-labour and education decisions.

\begin{tabular}{cccccc}
\hline \hline & $\eta$ & $\beta$ & $\gamma$ & $\alpha$ & $a$ \\
\hline$\sigma=1$ & 0.393 & 0.95 & 1.5 & 0.80 & 0.65 \\
$\sigma=2$ & 0.42 & 0.95 & 1.5 & 0.80 & 0.65 \\
\hline \hline
\end{tabular}

Table 2: Parameters for M.

$\mathrm{M}$ is a dynamic general-equilibrium model with heterogeneous agents. This agents, through discrete endogenous schooling decisions, transit from one state (low-skill) to

\footnotetext{
${ }^{16}$ The relative supply of skills is calculated from a sample that includes all workers between the ages of 18 and 65. It is defined as the ratio of college-equivalent to non-college-equivalent Autor and Krueger (1998)), using the number of weeks worked as weights. Here, a college-equivalent individual is exactly the same as college graduate plus one-half the number of workers with some college experience.

${ }^{17}$ Admittedly, the designations of the work force having only a high-school diploma as being 'unskilled' in contrast to the 'skilled' elite is rather crude, but we emphasize that these identifications merely serve as a manner of distinction in our model, and they do not express any judgment on their respective abilities, characters or qualifications.
} 
another (high-skill). The economy has two steady states: the initial state, in which there is only the old GPT $\left(n_{0}=0\right)$, and the final state, in which the new GPT has spread out across the entire economy $\left(n_{T}=1\right)$. Near these equilibria there are undetermined equilibria. In order to compute the recursive equilibrium numerically, we take $n_{0}>0$ initially, also to match empirical evidence, and the final $n_{T}$ close to unity. Because the individuals live $T=40$ periods (years), we assume that $V_{T+1}^{I}=0$. With that information and an estimate for $m_{T}$ we can solve $\mathrm{M}$ recursively with the Bellman equations for either category of workers. At each period, we are left with a nonlinear programming (NLP) that we solve with an accurate (global) optimization algorithm described in appendix B.

Table 3 summarizes the main results for $\mathrm{M}$ and in more detail in Figures 2 - 5 . In each Figure, the left-hand side displays the outcome for $\mathrm{M}$ with $\sigma=1$ and the righthand side the results with $\sigma=2$. All variables listed are endogenously determined by the model. However, although skills supply is endogenous it is also a state variable. As such, we have taken $m_{0}=0.27$, which is the actual value from 1969 (Census).

\begin{tabular}{c|ccc|ccc|ccc}
\hline \hline Model & \multicolumn{3}{|c|}{ US data } & \multicolumn{3}{c|}{$\mathrm{M}(\sigma=1)$} & \multicolumn{3}{c}{$\mathrm{M}(\sigma=2)$} \\
quantity & 1969 & 1980 & 1996 & 1969 & 1980 & 1996 & 1969 & 1980 & 1996 \\
\hline$w_{t}^{\mathrm{s}} / w_{t}^{\mathrm{u}}$ & 1.55 & 1.43 & 1.75 & 1.45 & 1.31 & 1.59 & 1.45 & 1.31 & 1.62 \\
$m_{t}$ & 0.27 & 0.43 & 0.57 & 0.27 & 0.38 & 0.66 & 0.27 & 0.36 & 0.63 \\
\hline \hline
\end{tabular}

Table 3: Comparison of the results for $\mathrm{M}$ with the data for the US.

Initially, the economy is in a steady state. In 1969, the relative supply of skills in the US is $27 \%$ and, according to our model (Table 3), the skill-biased technology accounts for $93 \%$ (1.45) of the skill premium observed (1.55). Then, suddenly, the diffusion of the skill-biased technology begins through all sectors and firms. Economic agents (households) foresee the technology diffusion and take it into account in their optimal decisions of consumption, schooling and labor supply during this economic transition.

Regarding the skill premium and the relative skills supply dynamics, the model exhibits the observed transitional dynamic path for both (see Table 3 , Figures 2 and 5). The US data indicate a slowdown in the SP between 1969 and 1979, which is also predictable by our model. However, our calibration exercise predicts that the slowdown lasts approximately three years longer. This difference is related to the fact that $n_{t}$ is still exogenous in our model; we have assumed a constant arrival rate for the template of the new GPT. M not only predicts the SP slowdown but also the acceleration in the SP after 1979. For example, during the US economic slowdown (1969 to 1980), the skill premium falls 12 percentage points while skills supply increases 16 percentage points. Our model, 
for $\sigma=1$, reports a fall of 14 percentage points for the skill premium and a rise of 11 percentage points for skills supply. For 1980, we predict that the skill premium and the relative skills supply are $1.31 \%$ and $0.38 \%$, respectively. So, a diffusion of $43 \%$ accounts for $92 \%$ and $82 \%$ of the real values of the skill premium and skills supply. Yet, along the US economic expansion (1980 to1996), the skill premium and skills supply increase 22 and 14 percentage points, respectively. Our model reports a rise of 28 percentage points for both premium and skills supply. However, according to our model, a diffusion of $83 \%$ still accounts for $90 \%$ of the real value of the skill premium in 1996, overestimating by $15 \%$ the skills supply.

Please observe that the skill premium (Figure 22) in the last ten years of the technology diffusion is relatively high compared to the real values, for which we offer three possible explanations. Firstly, the diffusion might not have been complete in the US because of market imperfections, for instance. Secondly, the firms evolve according to a Poisson distribution, which might reach its (final) plateau earlier than expected. Thirdly, redistributive policies might not allow for such a difference between the wages of the skilled and unskilled workers.

Nevertheless, both the slowdown and the subsequent sharp increase in the skill premium as well as the continuous increase in the skills supply are reproduced in our model. These results indicate that the agents maximize their lifetime utility correctly, and that they anticipate the effect of the technology diffusion by investing in educational activities prior to the acceleration of the diffusion. So, the model does relatively well in the reproduction of the slowdown, yet, as regards the expansion tends to overestimate the skills supply and consequently, underestimate the skill premium. This shows that to get an education is not free. Besides the implicit costs assumed, like disutility and forward earning scarifying consumption today, direct education costs could be assumed. For example, we could assume a tuition fee. Indeed, we cannot deny the role of the technology diffusion on the skill premium and schooling decisions. Contrary to pure technology theories, we show that schooling is an economic rational decision and it is not free. In summary, we have shown that in a general-equilibrium framework, the concept of the SBTC in conjunction with technological diffusion explains why there is an increase in the proportion of skilled individuals $m_{t}$ and, at the same time, the SP decreases between 1969 and 1979, and increases between 1980 and 1996.

Next we show the consumption dynamics. It is worth noting that both the skilled and unskilled subpopulations consume more if they are more averse to risks. Apart from the income inequality, which we have primarily analyzed so far, there is a consumption inequality because of the technology diffusion, as one can see in Figure 3. This side 

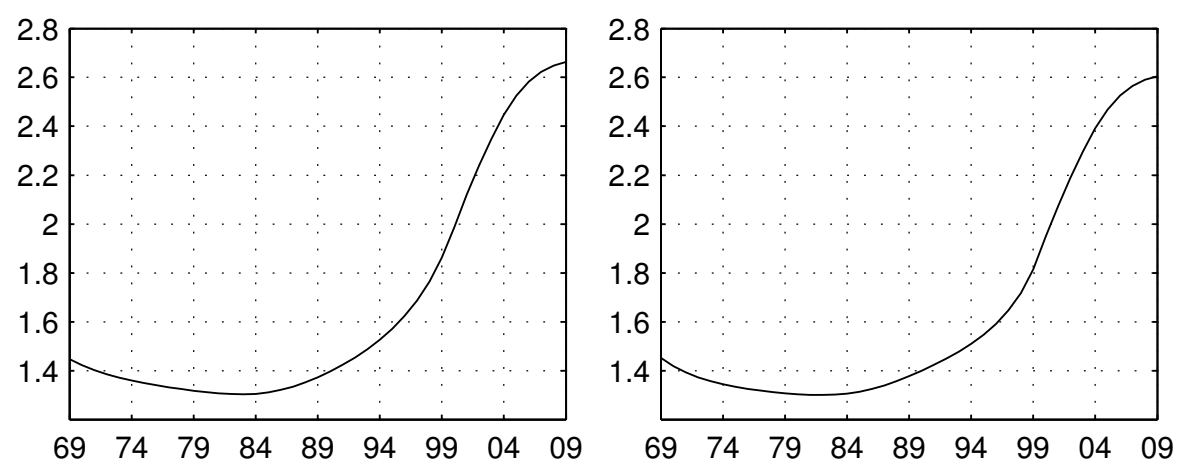

Figure 2: Evolution of the SP for the CES and logarithmic utility functions.

effect has not been researched in the partial-equilibrium analysis conducted by Aghion (2002); Acemoglu (2002); Krussel and Violante (2000); in the context of welfare and redistributive policies, the consumption inequality is actually more valuable, so that the link between the technological diffusion and the consumption inequality (intra and inter-temporal) is of vital importance. The consumption inequality is, in fact, slightly larger ${ }^{18}$ than the income inequality, with the exception of the first two years in our simulations. This discrepancy is associated with the higher labor supply by the skilled group, and the relative importance of substitution in comparison to income effects. Note that, although, in the real data, the overall consumption does not reflect this increase in inequality, one can observe a decline ${ }^{19}$ in an empirical decomposition of the 'within' consumption inequality and a sharp increase in the 'between' consumption inequality, which is not so different in magnitude from the income inequality (see e.g., Attanazio, 1999: Krueger and Perri, 2006). This suggests that changes in relative wages between education groups are mirrored in the changes in the consumption of these groups, as in the model results.

The supply of skilled (unskilled) labour increases (decreases) over time at a nonconstant rate (Figure 4) due to non-constant changes in the skill premium and profits. Furthermore, in roughly the first fifteen years of the new GPT diffusion, the unskilled laborers work more than skilled ones, whereas in the last twenty-five years or so the

\footnotetext{
${ }^{18}$ Unlike our model, in the real world households might borrow and lend, which avoids this excessive consumption inequality relatively to income inequality.

${ }^{19}$ Attanazio (1999) suggest that this decline of the 'within' consumption inequality is due to improved intra-group risk sharing, while the rise in the 'between' consumption inequality constitutes a falsification of the hypothesis of the between-group consumption inequality.
} 

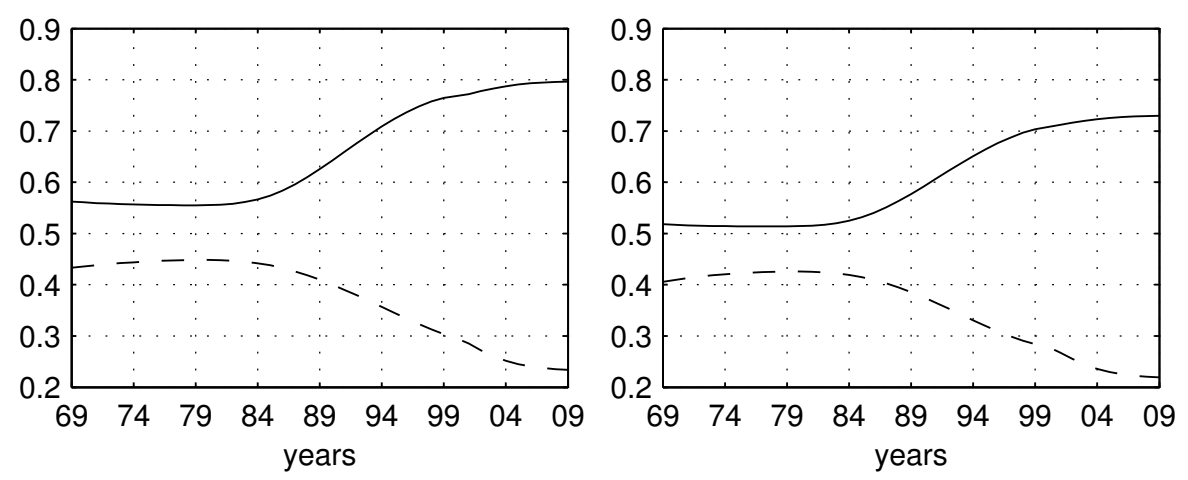

Figure 3: Evolution of the consumption for the CES and logarithmic utility functions; skilled (solid) and unskilled (dashed).

situation is reversed, supporting the real date 20 Erosa et al. (2009) and Heathcote et al. $(2010)$ ). This means that the skilled workers always consume more than their unskilled co-workers, as shown in Figure 3 , The income effect is visible in Figures 3 and 4 , where in the initial phase the wages $w_{t}^{\mathrm{s}}$ decrease and the amount of labour $l_{t}^{\mathrm{s}}$ increases. Subsequently, the skilled wages follow an upward trend, which is the substitution effect while unskilled wages follow a downward trend 21 as shown by empirical evidence. Similar behavior is observed in the results for unskilled personnel; since skilled and unskilled individuals have opposite reactions to changes in the wages, the resulting higher wage inequality exacerbates the consumption inequality (Figure 3). Regarding the investment in education (Figure 44), college-educated people work more than their high-school-educated colleagues, not only because of substitution/income effects, but also because their coworkers sacrifice their time to study.

Finally, we show the effect on schooling and human capital dynamics. The investment in education (Figure 4) and the human capital accumulation (Figure 5 tend to be proportional to the acceleration of the skill premium, which in turn means that it is proportional to the technological diffusion rate. Indeed, as soon as the technological diffusion rate decreases, and similarly the skill premium, we observe a slowdown in the

\footnotetext{
${ }^{20}$ Heathcote et al. (2010), using the households' budget constraints as a proxy for skill endowments, found a strong correlation between variance of log earnings and log hours, and an increase in the variance of the annual log hours, despite the fact that inequality in working hours for the group of white Caucasian males exhibits no obvious trend over the last forty years. Erosa et al. (2009), using, just as us, the years of education as proxy for the skill endowments, found that college educated people work less before the age of 26 and more afterwards, as predicted by our model. It is important to note, though, that our results show an excessive variance of working hours due to the absence of savings in our model.

${ }^{21} \mathrm{Graphs}$ for skilled and unskilled wage evolution available upon request.
} 

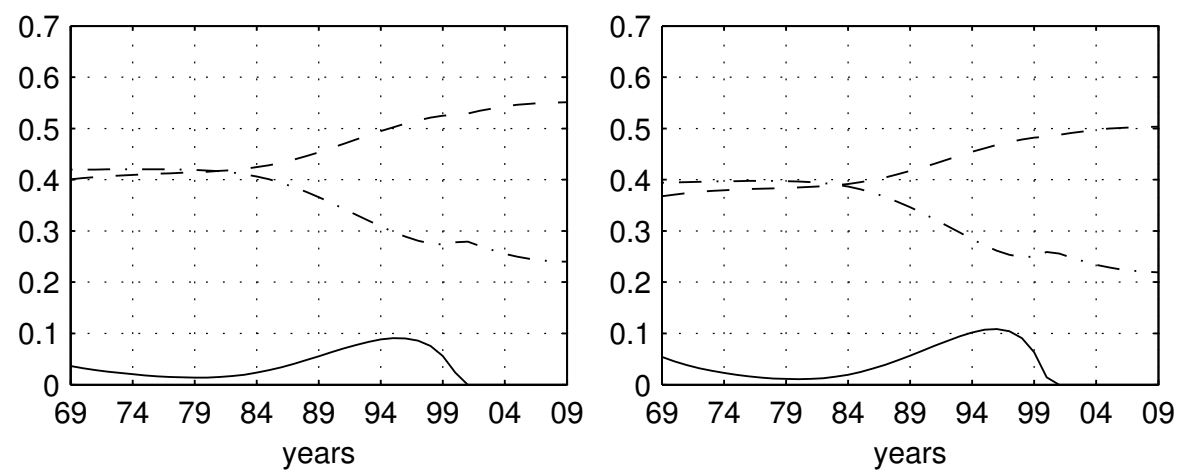

Figure 4: Evolution of the labour supply for the CES and logarithmic utility functions; education (solid), skilled (dotted) and unskilled (dashed).
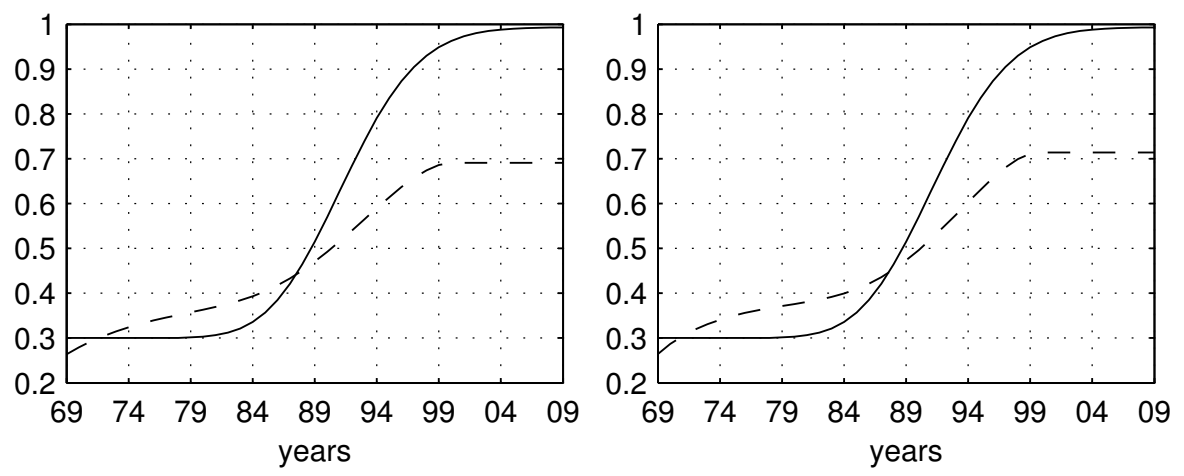

Figure 5: Evolution of the population and firms for the CES and logarithmic utility functions; firms (solid) and individuals (dashed). 
investment in education. The only exception is after $t=32$ (2001), where we observe a premature deceleration of the investment in education, despite the SP still accelerating. This fact is associated with the approximation of the individual's lifetime limit. Unskilled households reduce and stop their investment in education, as soon as their future returns do not compensate for their present cost of investment, i.e., reduction on their present consumption and income. This exception disappears when we increase their lifetime (see section 5). This allows us to state that investment is proportional to acceleration of technology diffusion. Note that the slowdown of technology diffusion is reflected in the investment in education. This feature is also found on the real data. Goldin and Katz (2007) show that after the 90s, the growth rate of college educated individuals has decreased.

Furthermore, M replicates the non-constant evolution observed in the evolution of the skills supply as described in Table1. In the US, the relative supply of college workers grew 2.86 percent per annum between 1960 and 1970, 4.91 percent a year between 1970 and 1980, and 2.69 percent annually from 1980 to 1990 (Goldin and Katz (2007)). In M initially, the relative supply of skills increases at a moderate rate, which turns into an acute rise that is followed by a final, continuous decrease.

\section{Calibration Sensitivity}

We have tacitly assumed that $T<\infty$, that is that individuals have finite lifetimes. This assumption is necessary in order to obtain a numerical solution. However, the main results are unaffected by the specific value of $T$. Numerous numerical simulations suggest that the model retains its characteristic features over extended periods of time. When $T$ tends to infinity, the returns of investment in education are unlimited and thereby, we end up with a fully educated workforce. The overall trends are not affected significantly by different risk aversion parameters.

We have set the productivity of the new GPT at 1.5 times that of the old GPT. Simulations show that for a range of different factors $(1.25 \leq \gamma \leq 1.75)$, we obtain a similar transition path that exhibits the same features as the original one. In the simulations shown, we have chosen $\alpha=0.8$, which means that the elasticity of substitution between skilled and unskilled workers is 5. Again, the overall trends do not change if we modify the elasticity to a smaller value of 1.67 Krussel and Violante (2000), which corresponds to $\alpha=0.4$. 


\section{Conclusion}

Despite the popularity of the pure technology theory to explain the skill premium in the US in the last 30 years, there are counter-factual predictions, such as the high productivity and non-decreasing behavior of unskilled workers. In addition, general equilibrium effects, elastic labor supply effects and education choices have been ignored in the research into the relationship between the skill premium and relative skills supply. In this paper, we define a general-equilibrium model with variable elasticity of labor supply, which incorporates the diffusion of an SBTC and discrete schooling decisions in order to explain the connection between the observed evolutions of the skill premium and relative skills supply.

In our model M, in which human capital accumulation and an SBTC diffusion are inbuilt, we have shown that we are able to recreate the overall trends in the skill premium and relative labor supply, as observed in the US over the last 30 years: an initial slowdown in the skill premium between 1969 and 1979, followed by a sharp increase between 1980 and 1990, and ended by a decrease of their growth rates from the 1990s onwards. The model also demonstrates that the relative labor supply of skilled relative to unskilled workers increases as a result of the dominance of the income effect, in spite of skilled laborers initially working less. Because of the wage differential, the higher-educated workforce consumes more and more in clear contrast to its lower-educated counterpart. Moreover, the static model shows that in the absence of savings, the diffusion of an SBTC generates a consumption inequality, which slightly dominates the wage inequality. Our model is able to match both the overall trends and the finer structures in the data for the US, showing that the individuals' decisions to invest in education are indeed a consequence of the diffusion of the SBTC. On the other hand, our model also reproduces the declines in unskilled wages. The biased demand of skilled intermediate goods, which are more profitable, and the spread of an SBTC along all sectors of the economy reduce the unskilled labor demand and their wages over time.

Additionally, our simulations indicate that in a finitely lived economy, we might end up with a partially educated workforce. Moreover, the higher the proportion of skills at the beginning of the diffusion process, the smaller the SP and the higher the proportion of skills at the end of the diffusion process, in finitely lived economies. This evidence suggests that economies that base their economic growth on the diffusion of new SBTC face a divergent economic growth process.

Although our results are consistent with empirical data, discrepancies have been noticed. In order to emulate the data more accurately, models that include savings, 
different (more realistic) education production functions, physical capital, externalities and real data for the SBTC are required. These are topics for future investigations.

\section{References}

Acemoglu, D. (1998). Why do new technologies complement skills? directed technical change and wage inequality. Quarterly Journal of Economics 113(4), 1055-1089.

Acemoglu, D. (2002). Technical change, inequality, and the labor market. Journal of Economic Literature 40(1), 7-72.

Aghion, P. (1998). Endogenous Growth Theory. The MIT Press - Massachusetts Institute of Technology.

Aghion, P. (2002). Schumpeterian growth theory and the dynamics of income inequality. Econometrica $70(3), 855-882$.

Aghion, P. and P. Howitt (2002). Wage inequality and the new economy. Oxford Review of Economic Policy 18(3), 306-323.

Arrow, K. J., H. B. Chenery, B. S. Minhas, and R. M. Solow (1961). Capital-labor substitution and economic efficiency. The Review of Economics and Statistics 43(3), $225-250$.

Attanazio, O. (1999). Consumption. In Handbook of Macroeconomics, Volume I, pp. 741-812. Elsivier Science B.V.

Auerbach, A. J. and L. J. Kotlikoff (1987). Life insurance of the elderly: Adequacy and determinants. NBER Working Papers 1737, National Bureau of Economic Research, Inc.

Autor, D., K. L. and A. Krueger (1998). Computing inequality: Have computers changed the labour market? Quarterly Journal of Economics 113, 1169-214.

Ben-Porath, Y. (1967). The production of human capital and the life cycle of earnings. The Journal of Political Economy 75(4), 352-365.

Berman, E., B. J. and Z. Griliches (1994). Changes in demand for skilled labour within us manufacturing: Evidence from annual survey of manufactures. Quarterly Journal of Economics 109(2), 367-97. 
Card, D. (1996). The effects of unions on the structure of wages: A longitudinal analysis. Econometrica 64, 957-79.

Chari, V. V. and L. J. Christiano (1994). Optimal fiscal-policy in a business-cycle model. Journal of Political Economy 102(4), 617-652.

Conesa, J. C., S. Kitao, and D. Krueger (2009). Taxing capital? not a bad idea after all! American Economic Review 99(1), 25-48.

Conesa, J. C. and D. Krueger (1999). Social security reform with heterogeneous agents. Review of Economic Dynamics 2(4), 757-795.

Erosa, A., L. Fuster, and G. Kambourov (2009). The heterogeneity and dynamics of individual labor supply over the life-cycle: Facts and theory.

Gali, J. (1995). Product diversity, endogenous markups, and development traps. Journal of Monetary Economics 36(1), 39-63.

Goldin, C. and L. F. Katz (1999). The returns to skill in the united states across the twentieth century. NBER Working Papers 7126, National Bureau of Economic Research, Inc.

Goldin, C. and L. F. Katz (2007). Long-run changes in the u.s. wage structure: Narrowing, widening, polarizing. NBER Working Papers 13568, National Bureau of Economic Research, Inc.

Gottschalk, P. and T. M. Smeeding (2000). Empirical evidence on income inequality in industrialized countries. In A. Atkinson and F. Bourguignon (Eds.), Handbook of Income Distribution, Volume 1 of Handbook of Income Distribution, Chapter 5, pp. 261-307. Elsevier.

Greenwood, J. and M. Yorukoglu (1997). 1974. Carnegie-Rochester Conference Series on Public Policy 46(1), 49-95.

Heathcote, J., F. Perri, and V. G.L. (2010). Unequal we stand: An empirical analysis of economic inequality in the united states: 1967-2006. Review of Economic Dynamics 13(1), 15-51.

Helpman, E. and M. Trajtenberg (1994). A time to sow and a time to reap: Growth based on general purpose technologies. CEPR Discussion Papers 1080, C.E.P.R. Discussion Papers. 
Howitt, P. (1998). Measurement, obsolescence, and general purpose technologies. In E. Helpman (Ed.), General Purpose Technologies and Economic Growth. Cambridge, MA: MIT Press.

Huang, H., S. Imrohoroglu, and T. J. Sargent (1997). Two computations to fund social security. Macroeconomic Dynamics 1(01), 7-44.

Jones, C. I. (1995). R-and-d-based models of economic-growth. Journal of Political Economy 103(4), 759-784.

Katz, L. F. and D. H. Autor (1999). Chapter 26 changes in the wage structure and earnings inequality. Volume 3, Part 1 of Handbook of Labor Economics, pp. 1463 1555. Elsevier.

Krueger, D. and F. Perri (2006). Does income inequality lead to consumption inequality? evidence and theory. Review of Economic Studies 73(1), 163-193.

Krussel, P., O. L. R.-R. J.-V. and G. Violante (2000). Capital-skill complementarity and inequality. Econometrica 41(3-5), 647-57.

Machin, S. (1997). The decline of labour market institutions and the rise in wage inequality in britain. European Economic Review 41(3-5), 647-57.

Murphy, K. and F. Welch (1992). The structure of wages. Quarterly Journal of Economics 107, 255-85.

Seegmuller, T. (2007). Taste for variety and endogenous fluctuations in a monopolistic competition model. Documents de travail du Centre d'Economie de la Sorbonne v07004, Universit Panthon-Sorbonne (Paris 1), Centre d'Economie de la Sorbonne.

Stokey, N. and R. Lucas (1996). Recursive methods in economic dynamics (4. print ed.). Cambridge, Mass.: Harvard Univ. Press.

Werning, I. (2007). Optimal fiscal policy with redistribution. Quarterly Journal of Economics 122, 925-967.

\section{A Optimisation Problem for the Firms}

Here, we consider the FOCs for the firms' optimization problem in more detail for M. We find the necessary optimality conditions for the final (see section 3.4) and intermediate 
producers (see section 3.5), and, in addition, explain how the real wages can be obtained by combining the labour demand with the labour market conditions 3.3 .

\section{A.1 Final Producers}

The final producers solve an optimization problem in a perfect competition environment. There is a unique final good that is produced with a continuum of intermediate goods (components) compatible with the GPT in use by the firms $j$. Final producers maximize their profits $\Pi_{t}$ with respect to $x_{t}^{\text {old }}(j)$ and $x_{t}^{\text {new }}(j)$. The (necessary) FOCs follow from the equations mentioned in section 3.4 , and are easily seen to be

$$
\begin{gathered}
P_{t} \gamma^{\alpha}\left[x_{t}^{\text {new }}(j)\right]^{\alpha-1}\left\{\int_{0}^{1}\left[x_{t}^{\text {old }}(j)\right]^{\alpha} \mathrm{d} j+\gamma^{\alpha} \int_{0}^{1}\left[x_{t}^{\text {new }}(j)\right]^{\alpha} \mathrm{d} j\right\}^{\frac{1}{\alpha}-1}-P_{t}(j)^{\text {new }}=0, \\
P_{t}\left[x_{t}^{\text {old }}(j)\right]^{\alpha-1}\left\{\int_{0}^{1}\left[x_{t}^{\text {old }}(j)\right]^{\alpha} \mathrm{d} j+\gamma^{\alpha} \int_{0}^{1}\left[x_{t}^{\text {new }}(j)\right]^{\alpha} \mathrm{d} j\right\}^{\frac{1}{\alpha}-1}-P_{t}(j)^{\text {old }}=0 .
\end{gathered}
$$

Alternatively, using equation (6), we find the relative prices of the intermediate goods $j$ produced with the new and old GPT

$$
\begin{gathered}
\frac{P_{t}(j)^{\text {new }}}{P_{t}}=\gamma^{\alpha}\left[x_{t}^{\text {new }}(j)\right]^{\alpha-1} Y_{t}^{1-\alpha}, \\
\frac{P_{t}(j)^{\text {old }}}{P_{t}}=\left[x_{t}^{\text {old }}(j)\right]^{\alpha-1} Y_{t}^{1-\alpha}
\end{gathered}
$$

respectively.

\section{A.2 Intermediate Producers}

Similarly, the FOCs for the intermediate producers using the new and old GPTs of section 3.5 are 


$$
\begin{array}{r}
\left(\frac{1}{\gamma}\right)^{\frac{1}{\alpha-1}}\left(\frac{P_{t}(j)^{\text {new }}}{P_{t}}\right)^{\frac{1}{\alpha-1}} Y_{t}+ \\
\left(P_{t}(j)^{\text {new }}-w_{t}(i)^{\mathrm{s}}\right)\left(\frac{1}{\gamma}\right)^{\frac{1}{\alpha-1}} \frac{1}{\alpha-1} \frac{1}{P_{t}}\left(\frac{P_{t}(j)^{\text {new }}}{P_{t}}\right)^{\frac{1}{\alpha-1}-1} Y_{t}=0, \\
\left(\frac{P_{t}(j)^{\text {old }}}{P_{t}}\right)^{\frac{1}{\alpha-1}} Y_{t}+\left(P_{t}(j)^{\text {old }}-w_{t}(i)^{\mathrm{u}}\right) \frac{1}{\alpha-1} \frac{1}{P_{t}}\left(\frac{P_{i t}^{\text {old }}}{P_{t}}\right)^{\frac{1}{\alpha-1}-1} Y_{t}=0,
\end{array}
$$

respectively.

From equations (29), we find the relative prices for the intermediate good $j$ created with either the new or old GPT. Due to monopolistic competition in the intermediate sector, prices are a mark-up over the marginal cost $\left(w_{t}\right)$. The higher the elasticity of substitution between intermediate goods produced with either the new or old GPT, the smaller the mark-up. Plugging these relative prices into the equations for the intermediate sector profits, we find the profits for the firms, as expressed by equation 11

\section{A.3 Labour Market Clearing}

In our economy, the labour demand arises from the intermediate sector. While the labour market is not segmented, we have only one labour market condition. As the new technology diffuses through the economy, the demand for skills increases, and the labour market becomes segmented. At that point we have two labour market conditions: one for unskilled and another for skilled workers.

\section{A.3.1 Unsegmented Market}

In the unsegmented market case, the wages for skilled and unskilled workers are equal. Therefore, there is only one labour market condition, for which the labour supply (4) is equal to the labour demand $\left(1-n_{t}\right) L_{t}+n_{t} L_{t}$. In order to the obtain real wages, we insert equations (8) into $L_{t}$ and $L_{t}$, and use $x_{t}^{\text {new }}(j)$ and $x_{t}^{\text {old }}(j)$ from equations (10):

$$
w_{t}=\alpha\left(\frac{n\left(\frac{1}{\gamma}\right)^{\frac{1}{\alpha-1}}+(1-n)}{l_{t}} Y_{t}\right)^{1-\alpha}
$$

We obtain wages as a function of labour hours supplied $l_{t}$, firms using the new GPT $n_{t}$ and output $Y_{t}$, as stated at the end of section 3.5 by substituting equations 10 into 
equation (6).

\section{A.3.2 Segmented Market}

The procedure is the same as for unsegmented markets. Now, there are two market clearing conditions, one associated with each type of GPT:

$$
\begin{aligned}
m_{t} l_{t}^{s} & =n_{t}\left(\frac{w_{t}^{s}}{\alpha \gamma^{\alpha}}\right)^{1 /(\alpha-1)} Y_{t} \\
w_{t}^{s} & =\alpha \gamma^{\alpha}\left(\frac{n_{t} Y_{t}}{m_{t} l_{t}^{s}}\right)^{(1-\alpha)} \\
\left(1-m_{t}\right) l_{t}^{s} & =\left(1-n_{t}\right)\left(\frac{w_{t}^{u}}{\alpha}\right)^{1 /(\alpha-1)} Y_{t} \\
w_{t}^{u} & =\alpha\left(\frac{\left(1-n_{t}\right) Y_{t}}{\left(1-m_{t}\right) l_{t}^{u}}\right)^{1-\alpha} .
\end{aligned}
$$

Afterwards, we substitute $w_{t}^{s}$ and $w_{t}^{u}$ into output equation (6), and derive the output, in function of $\left(l_{t}^{s}, l_{t}^{u}\right), m_{t}$ and $n_{t}$.

$$
\begin{aligned}
Y_{t} & =\left(\int_{0}^{1-n_{t}}\left(x_{t}^{\text {old }}(j)\right)^{\alpha} d_{j}+\gamma^{\alpha} \int_{1-n_{t}}^{1}\left(x_{t}(j)^{\text {new }}\right)^{\alpha} d_{j}\right)^{1 / \alpha} \\
& =\left(\left(1-n_{t}\right)\left(\frac{\left(1-n_{t}\right)}{\left(1-m_{t}\right) l_{t}^{u}}\right)^{-\alpha}+\gamma^{\alpha} n_{t}\left(\frac{n_{t}}{m_{t} l_{t}^{s}}\right)^{-\alpha}\right)^{1 / \alpha} \\
& =\left(\left(1-n_{t}\right)^{(1-\alpha)}\left(\left(1-m_{t}\right) l_{t}^{u}\right)^{\alpha}+\gamma^{\alpha} n_{t}^{(1-\alpha)}\left(m_{t} l_{t}^{s}\right) \alpha\right)^{1 / \alpha} .
\end{aligned}
$$

\section{B Computational Method}

The problem $\mathrm{M}$ is a finite-horizon discrete-time dynamic optimization problem. At each phase (period) $t=0, \ldots, T$ with $T \geq 0$, the dynamic variables $m_{t+1}$ and $n_{t+1}$, and the value functions $V_{t+1}^{I}$ are (assumed to be) known. Since, all agents live $T$ periods, we have that $V_{T+1}^{I}=0$. Initially, we guess $m_{T}$, and refine its value after each optimization according to the computed value $m_{0}$. In that way we obtain a sequence of $(T+1)$ nonlinear programming problems, which can be solved by backward induction, as is commonly done. By virtue of the principle of optimality, the solution found with the dynamic programming approach is the global optimum of the original problem.

We obtain the solution by using a a hybrid combination of a genetic algorithm (GA) 
and a sequential quadratic programming (SQP) algorithm. The nonlinear constraints are incorporated in both algorithms by using a merit function that consists of the objective function as well as the nonlinear constraints through penalty functions. The genetic algorithm, being a global search heuristic, is used to generate an estimate of the global optimum at each phase, after which the SQP algorithm takes over, and refines the solution solving a quadratic programming subproblem with an active-set algorithm at each iteration. At each iteration the Hessian of the Lagrangian, that is the objective function of the nonlinear programe (NLP) augmented by the sum of the individual constraints functions with corresponding Lagrange multipliers, is updated with the quasiNewton Broyden-Fletcher-Goldfarb-Shanno (BFGS) formula, which is known to have quadratic convergence near the optimum.

In genetic algorithms, points in the search space, that is the (feasible) domain of the NLP, are identified with individuals of a certain population. All individuals are assigned a value, called fitness, that is directly related to the objective function of the NLP. In order to evolve (iteratively) towards a healthier population, a set of so-called genetic operators that select, merge and modify the properties of the poptaulation is required. The selection operator chooses a group of individuals for 'reproduction' based on their fitness, whilst the remaining ones are eliminated from the population. The selection operator determines which individuals are chosen to produce progeny and which ones are allowed to move on to the next generation unaltered, which is known as elitism. The actual 'reproduction' is accomplished by the crossover operator, which combines the individuals to form new ones that replace the ones eliminated. The reproduction phase is completed by random mutations of the individuals at a set rate; mutation is required to preserve the diversity, that is to prohibit premature convergence to a local optimum. This three-stage process is repeated until some specified termination criterion is satisfied.

The main advantage of our hybrid method lies in the fact that the GA generates an approximation of the global optimum, which is necessary to start the local SQP optimizer in order to guarantee convergence; the quality of the initial guess is crucial to the success of the optimization algorithm, yet an accurate initial guess is usually difficult to provide for a generic NLP. It is clear that the hybrid approach is robust, as the initialization, which depends highly on the characteristics of the NLP under consideration, is independent of the structure of the NLP, yet it yields precisely the information needed to proceed with deterministic algorithms that are more efficient near the optimum.

The structure of the algorithm we have used in our computations is shown schem- 
atically in Figure 6. Once the model has been calibrated, and the algorithms have been initialized, the optimization sequence starts at phase $t=T$. The GA attempts to find the global optimum and once it has found a candidate solution to the NLP, it passes that solution as an initial guess to the SQP algorithm, which in turn refines the solution and returns the global optimum of the NLP. It might be possible that the GA is unable to close in on the optimum due to for instance an infeasible initial population or too stringent tolerances, so we have allowed for the possibility to automatically restart the GA several times with different linearly feasible yet random initial populations. The solution found in the segmented market structure determines whether the algorithm stores and sets all values for the subsequent phase immediately $\left(w_{t}^{\mathrm{u}}<w_{t}^{\mathrm{s}}\right)$, or proceeds with the optimization in the unsegmented market structure first $\left(w_{t}^{\mathrm{u}} \geq w_{t}^{\mathrm{s}}\right)$. The optimization sequence is repeated from phase $t=T$ to $t=0$, after which the dynamic programe has been solved.

In our implementation of the GA we have chosen a tournament selection operator, where a uniformly distributed sample of individuals is compared based on their ranks in the population rather than their fitness values. In each sample the best individual is selected for reproduction. Crossover between selected individuals is done by creating a child solution that lies on the line through the parent solutions at two-fifths the distance between both parents from the parent with the best fitness value, in the direction of increasing fitness. The mutation operator adds random values in directions that are adaptive with respect to the previous generation yet respect the variable bounds and linear constraints. Elitism has been incorporated to ensure that the best individuals of each population propagate. The GA stops successfully if the constraints violation is smaller than the given tolerance, and if either the average (cumulative) fitness value has not changed over 20 generations or the change in the variables becomes smaller than the internal precision.

In Table 4 we have listed some relevant parameters for the GA and SQP algorithms. The entries 'generations', 'iterations' and 'evaluations' refer to the maximum number of generations, iterations and objective function evaluations, respectively. The tolerances for both algorithms indicate the maximum allowed constraints violation. With these settings, we obtain a solution in approximately one minute on an Intel $\mathbb{R}$ Core ${ }^{\mathrm{TM}} 2$ $2.13 \mathrm{GHz}$ processor with $2 \mathrm{~GB}$ of RAM. Larger populations yield a better coverage of the search space, and hence have a better chance of finding the global minimum; for a population of 40 individuals the computation takes on average between two and three minutes. Less than $10 \%$ of the actual CPU time is spent on the SQP algorithm, so that for large populations the GA clearly becomes the bottleneck in the optimization. We 


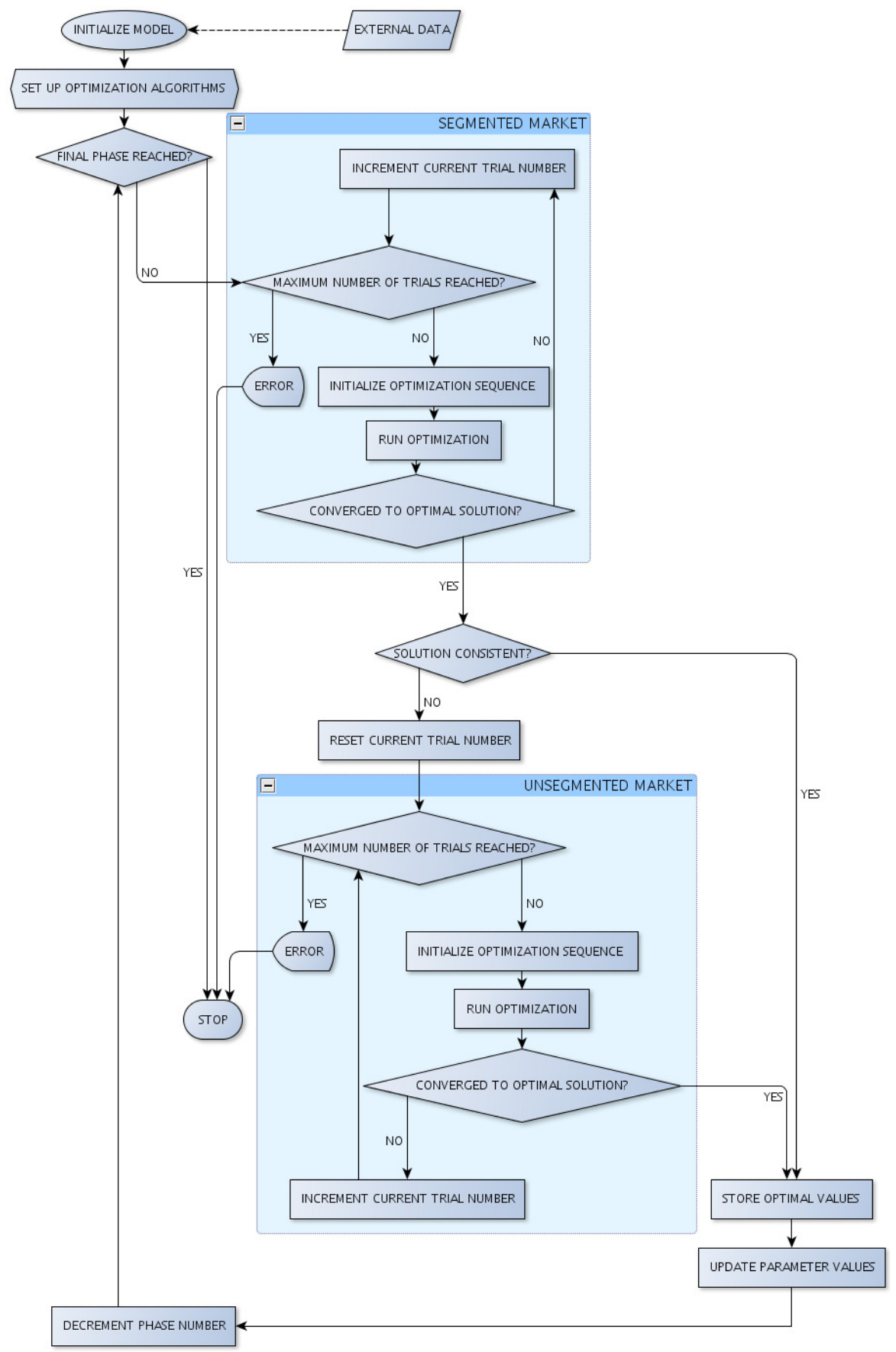

Figure 6: Graphical representation of the structure of our algorithm. 


\begin{tabular}{lr|ll}
\hline \hline \multicolumn{1}{c|}{ GA } & \multicolumn{2}{c}{ SQP } \\
\hline generations & 1000 & iterations & 1000 \\
population & 20 & evaluations & 10000 \\
elite individuals & 2 & tolerance & $10^{-10}$ \\
tournament size & 4 & & \\
trials & 10 & & \\
tolerance & $10^{-6}$ & & \\
crossover fraction & 0.70 & & \\
\hline \hline
\end{tabular}

Table 4: Parameters used for the genetic and sequential quadratic programming algorithms.

note, however, that we have not seen significant changes in the results for populations larger than 40, so that we are confident that the hybrid optimization procedure finds the global optimum at each stage. The numerical solution is usually found in the first trial, and more trials are only required for more stringent tolerances on the side of the GA.

\section{Proofs}

\section{C.1 Growth Rates}

In order to arrive at the results stated in propositions 2 and 3 , we need to introduce the concept of a discrete growth rate and establish the herewith related rules to facilitate the calculation of growth rates for generic functions. The reader familiar with continuous growth rates is encouraged to review the rules for composite functions in continuous time, and compare these to the ones derived below for the case of discrete time.

Let $\mathbb{F}, \mathbb{R}$ be all maps (i.e. functions) from a field $\mathbb{F}$ to the reals. If $\mathbb{F}=\mathbb{Z}$ we speak of discrete functions, whereas if $\mathbb{F}=\mathbb{R}$ we speak of (real-valued) continuous ones. The growth rate of a function $f: \mathbb{Z}, \mathbb{R} \rightarrow \mathbb{R}$, at time $t \in \mathbb{Z}$ is defined by

$$
\widehat{f}\left(x_{t}\right):=\frac{f\left(x_{t+1}\right)-f\left(x_{t}\right)}{f\left(x_{t}\right)},
$$

where $x_{t} \in \mathbb{Z}, \mathbb{R}$. Henceforth, we shall omit the arguments where possible, and we consider the functions $f, g, h: \mathbb{Z}, \mathbb{R} \rightarrow \mathbb{R}$.

Lemma 1. If $f=\lambda g$, with $\lambda \in \mathbb{R}$, then $\widehat{f}=\widehat{g}$. 
Proof. This follows immediately from the definition (31):

$$
\begin{aligned}
\widehat{f} & =\frac{\lambda\left(g\left(x_{t+1}\right)-g\left(x_{t}\right)\right)}{\lambda g\left(x_{t}\right)} \\
& =\frac{g\left(x_{t+1}\right)-g\left(x_{t}\right)}{g\left(x_{t}\right)} \\
& =\widehat{g} .
\end{aligned}
$$

Lemma 2. If $f=g \cdot h$, then $\widehat{f}=\widehat{g} \widehat{h}+\widehat{g}+\widehat{h}$.

Proof.

$$
\begin{aligned}
\widehat{f} & =\widehat{g h} \\
& =\frac{g\left(x_{t+1}\right) h\left(x_{t+1}\right)-g\left(x_{t}\right) h\left(x_{t}\right)}{g\left(x_{t}\right) h\left(x_{t}\right)} \\
& =\frac{g\left(x_{t+1}\right) h\left(x_{t+1}\right)}{g\left(x_{t}\right) h\left(x_{t}\right)}-1 \\
& =\frac{g\left(x_{t+1}\right)}{g\left(x_{t}\right)} \frac{h\left(x_{t+1}\right)}{h\left(x_{t}\right)}-1 \\
& =\left(\frac{g\left(x_{t+1}\right)}{g\left(x_{t}\right)}-1\right)\left(\frac{h\left(x_{t+1}\right)}{h\left(x_{t}\right)}-1\right)+\frac{g\left(x_{t+1}\right)}{g\left(x_{t}\right)}+\frac{h\left(x_{t+1}\right)}{h\left(x_{t}\right)}-2 \\
& =\left(\frac{g\left(x_{t+1}\right)-g\left(x_{t}\right)}{g\left(x_{t}\right)}\right)\left(\frac{h\left(x_{t+1}\right)-h\left(x_{t}\right)}{h\left(x_{t}\right)}\right)+\left(\frac{g\left(x_{t+1}\right)}{g\left(x_{t}\right)}-1\right)+\left(\frac{h\left(x_{t+1}\right)}{h\left(x_{t}\right)}-1\right) \\
& =\widehat{g} \widehat{h}+\widehat{g}+\widehat{h} .
\end{aligned}
$$

Lemma 3. If $f=g^{k}$, and $k \in \mathbb{R}$ then

$$
\widehat{f}=(\widehat{g}+1)^{k}-1 \text {. }
$$


Proof.

$$
\begin{aligned}
\widehat{f} & =\widehat{g^{k}} \\
& =\frac{g^{k}\left(x_{t+1}\right)-g^{k}\left(x_{t}\right)}{g^{k}\left(x_{t}\right)} \\
& =\frac{\left(g\left(x_{t}\right)(\widehat{g}+1)\right)^{k}-g^{k}\left(x_{t}\right)}{g^{k}\left(x_{t}\right)} \\
& =\frac{g^{k}\left(x_{t}\right)(\widehat{g}+1)^{k}}{g^{k}\left(x_{t}\right)}-1 \\
& =(\widehat{g}+1)^{k}-1 .
\end{aligned}
$$

Lemma 4. If $f=g+h$, then

$$
\widehat{f}=\widehat{g}+\widehat{h}+\frac{g \widehat{h}+h \widehat{g}}{g+h} .
$$

Proof. The result is easy to verify with the substitution $g\left(x_{t+1}\right)=g\left(x_{t}\right)(\widehat{g}+1)$, an analogous one involving $h$, and subsequent algebraic simplifications.

Lemma 5. If $f=g / h$, with $h \neq 0$, then

$$
\widehat{f}=\frac{\widehat{g}}{\widehat{h}}+\frac{\widehat{g}+\widehat{h}^{2}}{\widehat{h}+\widehat{h}^{2}}
$$

Proof. A consequence of lemmata 2 and 3 with $k=-1$.

Now, we are able to compute the growth rates of the wages of the skilled and unskilled individuals. Define $y_{t}=Y_{t}\left(m_{t} l_{t}^{\mathrm{s}}\right)$, and $y_{t}=Y_{t} /\left(\left(1-m_{t}\right) l_{t}^{\mathrm{u}}\right)$, as in section 3.5 . The application of lemmata 12 and 5 leads immediately to the results mentioned in proposition 2 .

Similarly, one can easily derive proposition 3, which requires some simplifications that can be done most easily with the aid of any modern computer algebra system. Alternatively, one can easily see that

$$
\begin{aligned}
\widehat{S P} & =\gamma^{\alpha}\left(\frac{n_{t}}{1-n_{t}} \frac{1-m_{t}}{m_{t}} \frac{l_{t}^{\mathrm{u}}}{l_{t}^{\mathrm{s}}}\right)^{1-\alpha} \\
& =(1+\widehat{N}+\widehat{M}+\widehat{\Lambda}+\widehat{N} \widehat{M}+\widehat{N} \widehat{\Lambda}+\widehat{M} \widehat{\Lambda}+\widehat{N} \widehat{M} \widehat{\Lambda})^{1-\alpha}-1
\end{aligned}
$$


where $N=n_{t}\left(1-n_{t}\right), M=\left(1-m_{t}\right) m_{t}$, and $\Lambda=l_{t}^{\mathrm{u}}\left(l_{t}^{\mathrm{s}}\right)$. 